\title{
VINOS EN CHILE DESDE LA INDEPENDENCIA HASTA EL FIN DE LA BELLE ÉPOQUE ${ }^{* *}$
}

La producción, importación y consumo de vinos experimentaron cambios significativos en el período que va entre la Independencia y la víspera de la Primera Guerra Mundial. En este trabajo se estudia la introducción de nuevas cepas y los cambios en las técnicas de vinificación desde mediados del siglo XIX. El desglose de las cifras de producción anual por provincia permite apreciar la difusión de las nuevas cepas, mientras que testimonios contemporáneos advierten sobre las diferencias en las calidades del producto. Las cifras de importación para los distintos tipos y envases de vinos reflejan estos cambios. La internación de tintos a granel experimenta una caída sistemática desde la década del 1870, no así el champaña que aún no se fabricaba en Chile. Más significativa es la creciente figuración de los vinos nacionales en los menús de los banquetes oficiales y sociales en el período.

Palabras clave: vinos, viñas, vitivinicultura historia cultural, historia económica.

The production, imports and consumption of wine underwent significant changes in the years between Independence and the eve of the First World War. This article studies the introduction into Chile of new varieties of vines, and changes in winemaking techniques from the middle of the $19^{\text {th }}$ century onwards. Annual production figures from the different provinces show the gradual penetration of the new varieties, and contemporary sources attest to the differences in the quality of the wines. Import figures for the different types of wine reflect these changes. Imports of plain red wines, though not for champagnes, show a steady decline from the 1870s. More tellingly, Chilean wines were increasingly served in official and social banquets during this period as indicated in the corresponding menus.

Key words: wine, vinyards winemaking, cultural history, economic history.

La vitivinicultura en Chile ha cobrado creciente desarrollo en Chile en la última década, el que ha ido a la par con el aumento de las exportaciones. El cultivo de la historia del vino, empero, no ha tenido un desenvolvimiento tan espectacular después de la excelente Historia del Vino Chileno de José del Pozo publicada en 1998.

\footnotetext{
Profesor del Instituto de Historia de la Pontificia Universidad Católica de Chile. Correo electrónico: jcouyoum@puc.cl

** El presente trabajo forma parte del proyecto Fondecyt 1030873. Era la intención del autor de que fuera publicado en el $N^{\circ} 38 / 2$ de esta revista en homenaje a la memoria de don Javier González, 1o que no pudo ser. Vaya pues este artículo en homenaje al recordado maestro.
} 
El presente artículo busca dar una idea sobre el alcance que tuvo la renovación de los vinos chilenos frente a los productos importados y el consumo nacional durante el siglo XIX, sin pretender agotar el tema.

En la época de la Independencia y hasta mediados del siglo XIX los vinos más afamados de Chile provenían de la provincia de Concepción, una reputación que parece explicarse principalmente por el menor rendimiento de las vides. Sobre esto último, Claudio Gay señala que mientras en Chillán seis vides en toda producción daban un galón de mosto, en Santiago daban seis y en Aconcagua ocho. Este mayor rendimiento se lograba con más riego; en cambio las viñas del sur eran de rulo ${ }^{1}$.

Las variedades de uvas que se conocían en Chile hasta la primera mitad del siglo XIX y antes de la introducción de las cepas francesas, eran las siguientes ${ }^{2}$ :

Uva común o del país
Uva de San Francisco
Uva cristalina blanca
Uva Italia blanca
Uva rosada común

Uva común o del país

Uva uña de gallo

Uva aceituna

Uva Italia negra moscatel

Uva del Huayco

Uva rosada moscatel de Curacaví

Aunque los vinos chilenos encontraban buena demanda en la población, los testimonios de viajeros extranjeros de la época concuerdan en que su calidad dejaba bastante que desear. Alexander Caldcleugh, que visitó Chile a comienzos de los años 1820 , declara.

El vino en general es solo regular. El que se hace cerca de Concepción, llamado vino de Penco, considerado el mejor, es el que más se parece al Málaga de cuantos vinos se conocen en Europa ${ }^{3}$

Lo mismo opinaba el agente norteamericano Teodorico Bland, quien calificaba los procesos para preparar el vino de "groseros, toscos y malos", sin perjuicio de rescatar "un excelente vino fabricado con esmero en Penco, cerca de Concepción y otros vinos preparados cerca de Coquimbo"4. Nada había mejorado en los años siguientes. P. Campbell Scarlett escribiendo en la década de 1830 señala que la uva se daba bien en Chile, pero que no sabían vinificarla: "El vino de Chile es muy inferior al de Mendoza" . Reitera este juicio al hablar del intenso cultivo de la vid

1 Claudio Gay, Agricultura Chilena. Edición facsimilar de la Historia Física y Política de Chile, introducción, bibliografía e iconografía de Sergio Villalobos, R., Santiago, ICIRA, 1973, 2 vols. II, 201-202; José del Pozo, Historia del vino chileno, Santiago, Editorial Universitaria, 1998, 53-54.

2 Manuel Rojas L., Tratado de Viticultura y Vinificación (segunda edición), Santiago, Imprenta y Encuadernación Barcelona, 1897, 12. La primera edición de esta obra parece ser la de Talca, 1891 (482 pp.) y hay otra de 1892. Agradezco esta referencia a María José Dulcic.

Samuel Haigh, Alejandro Caldcleugh, Max Radiguet, Viajeros en Chile 1817-1847, Santiago, Editorial del Pacífico, 1955, 149, 156.

4 Teodorico Bland, Descripción Económica i Política de Chile en el año de 1818, traducida por Domingo Amunátegui Solar, Santiago, Establecimientos Gráficos de Balcells \& Co, 1926, 16.

5 P. Campbell Scarlett, Viajes por América a través de las Pampas y los Andes, Buenos Aires, Editorial Claridad, 1957, 138. 
en Quillota, agregando que "los nativos no son muy afortunados en la elaboración del vino"6.

Al parecer los mayores logros estaban en la fabricación de un vino blanco dulce. Al juicio de Caldcleugh se suma el comentario de María Graham sobre los logros de Francisco de la Lastra dueño de una hacienda entre Santiago y El Salto: "Ha conseguido fabricar un vino apenas inferior al champaña y una imitación del vino de Madeira comparable con el mejor vino tinto de Tenerife" 7 . Thomas Sutcliffe también pondera el vino blanco de la chacra Apoquindo de Francisco de la Lastra y Max Radiguet, que visitó Valparaíso en 1847, confirma que los vinos dulces de Concepción eran los más estimados ${ }^{8}$.

Juan María Mastai Ferretti que visitó Chile en 1824, atribuía el problema de la calidad al proceso de elaboración. Declara que, en general, "el vino es muy pesado porque es cocido y lo guardan con cal en vasijas de barro". ${ }^{9}$ En efecto, el procedimiento de fabricación de vino, descrito por John Miers, Claudio Gay y otros, y que José del Pozo ha recogido en su Historia del vino chileno, permite formarnos una idea de la calidad resultante.

La uva era cosechada a fines de abril, y debido a lo tardío de la fecha era necesario realizar la faena con la mayor premura posible para anticiparse a las lluvias. Los racimos eran transportados en capachos en lomo de mula hasta la bodega. Allí era depositada en lagares de ladrillo o de cuero montado sobe un bastidor, donde eran pasadas por una criba y desgranadas, descartando el escobajo. Al término de la jornada, cuando terminaba la recolección, la uva era pisoteada por hombres tal como se hacía en el sur de Europa, si bien en las haciendas más grandes de la zona de Concepción se usaban caballos para el prensado.

Extraído el jugo, los orujos y lo que quedaba eran pasados a otro lagar o a la parte superior del mismo, y colocados sobre un "cincho", especie de tejido de gruesas varillas con látigo, y prensado varias veces con tablas sobre las cuales se colocaban gruesas piedras, y, según Miers, machacado con combos. El jugo adicional extraído también pasaba a las cubas de fermentación a mezclarse con el anterior ${ }^{10}$.

En las provincias centrales y septentrionales, el orujo, con o sin el escobajo, se destinaba a la destilación. Este último proceso, que se realizaba en la misma hacienda, arrojaba muy buenos beneficios y podía llegar a costear todos los gastos de la fabricación del vino. La destilación era también el destino de aquellos vinos que se habían estropeado, algo que sucedía con cierta frecuencia. Claudio Gay observa que al hacer el vino "sin escobajos ni hollejos", este toma "un color más o menos pajizo”. En cambio, en la provincia de Concepción,

\section{Ibíd. 144.}

7 María Graham, Diario de mi residencia en Chile, Santiago, Editorial del Pacífico, 1956. 118.

8 Samuel Haigh, Alejandro Caldcleugh, Max Radiguet, Viajeros en Chile 1817-1847, Santiago, Editorial del Pacífico, 1955, 247.

9 Juan María Mastai-Ferretti, "Diario de viaje a Chile de .... (Pío IX)" Traducido y anotado por Fr. Carlos Oviedo Cavada, I.C.D., S.T.L., Historia 1, 1961, 247.

10 Del Pozo [1], 48; Claudio Gay [1], II, 190.-191; John Miers, Travels in Chile and La Plata, London, Printed for Baldwin, Cradock and Joy, 1826, II, 297-299, Edmond R. Smith, The Araucanians, or notes of a tour among the Indian tribes of Southern Chili. New York, Harper \& Brothers, publishers, 1855. 103 . 
donde quedan generalmente los escobajos o a lo menos los hollejos mezclados con el mosto, los vinos son... más o menos oscuros según la localidad y la cantidad de unos y otros que se conservan en el líquido ${ }^{11}$.

Miers anota que todos los vinos chilenos, blancos y tintos, se fabricaban a partir de la uva negra. Este último era una imitación del carlón de Cataluña. Para extraer el color del hollejo en su elaboración se agregaba yeso quemado, lo que daba al vino un sabor astringente ${ }^{12}$. La costumbre de agregar yeso al vino parece haber persistido en el tiempo, pues la ordenanza que reglamentaba el expendio de artículos alimenticios en Valparaíso a fines del siglo XIX, disponía que "el empleo de yeso en la elaboración de los vinos es un procedimiento que se declara proscrito" y lo mismo hacía con el carbonato de cal ${ }^{13}$.

Una parte del jugo obtenido en la primera prensada se destinaba a fabricar arrope o "cocido", como se le llamaba. Según Radiguet, este se hace hervir en una caldera hasta que tomara la consistencia de un jarabe. Miers informa que el mosto se hervía en pailas de cobre hasta quedar reducido a los dos tercios del volumen original. La violenta llama del fuego -agrega- "le comunica un fuerte sabor empireumático, que se transmite al vino" 14 . Gay, por su parte, señala que se hacía hervir el mosto hasta quedar reducido a la tercera parte de su volumen "y a veces después de haberlo clarificado con claras de huevo o ceniza". Sin embargo, acota,

esta operación exige mucha habilidad de parte del que la ejecuta por la facilidad con que el líquido se quema, lo que daría muy mal gusto al licor; así pues se contentan frecuentemente con darle un ligero hervor o colocarlo sobre un fuego lento a fin de no evaporarlo mucho ${ }^{15}$.

El "cocido" era vaciado en tinajas de greda y mezclado con el mosto en una proporción variable. Radiguet habla de una parte de cocido por tres partes de mosto, mientras que Miers señala una proporción de uno a diez. La razón para hacer esta mezcla, según Miers, es que de otro modo el vino resultaría agrio por cuanto la uva no contiene suficientes sustancias azucaradas para generar la cantidad necesaria de alcohol que asegure su preservación. Esta falta de azúcar, agrega, se debe al excesivo regadío de las viñas en el afán de obtener una mayor producción. Él mismo deja esto en evidencia cuando cuenta que solía comprar "sancochado", es decir, chicha con adición de cocido, y "agregándole azúcar y observando cuidadosamente su fermentación, he hecho vinos de modo alguno inferiores al mejor Tenerife"16. Edmund R. Smith, que recorrió las provincias del sur hacia

11 Claudio Gay [1], II, 191. ver tb. Id. II, 197.

12 Del Pozo [1] 51; Miers [9], II, 301.

13 Arts. 14 y 15 de la "Ordenanza que reglamenta el espendio de los artículos alimenticios en la ciudad de Valparaíso”. Almanaque Guía Nacional para 1890. Valparaíso, Imprenta La Patria, 1890, 117.

14 Miers [9], II, 300; Del Pozo [1], 51.

15 Gay [1] II, 192; Haigh, Caldcleugh y Radiguet [7], 247.

16 Miers [9], II, 300-301. 
1850 y observó el proceso de vinificación, hace la misma observación sobre la falta de alcohol que hacía necesaria la adición de arrope ${ }^{17}$.

Comentando sobre la calidad del producto local señala:

Los "mostos" [sic] de las provincias del sur son gruesos y algo parecidos al oporto; pero como rara vez se guardan por más de un año, les falta uno de los elementos esenciales para los buenos vinos -es decir, la edad-para que tengan el sabor de las marcas europeas más celebradas ${ }^{18}$.

El empleo de tinajas de greda también atentaba contra la calidad. Para impedir su filtración, estas vasijas eran recubiertas en su interior con brea o resina, que comunicaba su sabor al vino durante el proceso de fermentación, aunque es posible que en el caso de las tinajas viejas, la borra acumulada con el paso de los años amortiguara el efecto del sellante. Gay señala, además, que las tinajas se dejaban abiertas, lo que hacía que los vinos perdieran su aroma. Por otra parte, estimaba que estos vinos

Son menos susceptibles de oxigenarse con el tiempo, desde luego a causa de la espuma que cubre su superficie, lo que los libra de las alteraciones pútridas que el oxigeno del aire les ocasiona... ${ }^{19}$

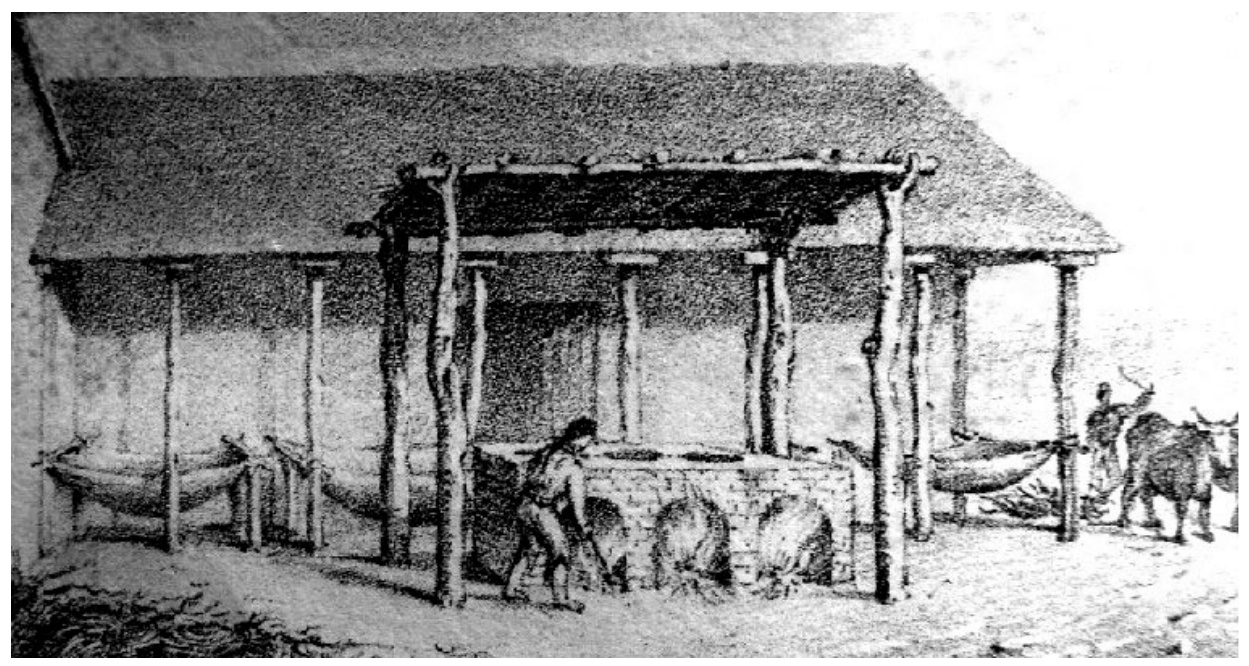

Preparando el "cocido". Al fondo los lagares descritos por Miers. En John Miers, Travels in Chile and La Plata, London, Printed for Baldwin, Cradock and Joy, 1826, Vol. II, frente a p. 297.

\footnotetext{
17 Smith [9], 103.

18 Ibíd.

19 Gay [1], II, 191-192.
} 
Miers y Smith informan que, luego de fermentado el vino en las tinajas, estas se cubrían con una tapa de greda sellada con una pasta de arcilla mezclada con guano de caballo o con brea. De más está decir que estos aromas también se comunicaban al producto. Gay señala que las vasijas también solían ser selladas con un cuero atado con un látigo ${ }^{20}$. El sabio francés añade que

Las bodegas donde se hallan depositadas las tinajas ofrecen, asimismo, un gran inconveniente, porque situados en un piso al nivel del patio con las puertas frecuentemente abiertas al aire, el vino queda expuesto a todas las variaciones [diarias] de la temperatura que son siempre muy intensas en el Norte y en las provincias centrales y que alcanzan a veces hasta 20 grados de diferencia y más ${ }^{21}$.

Luego venía el transporte que también deterioraba el sabor del producto. Dice Gay:

La mala calidad de los caminos hace que aún se sirvan de odres, cuya capa interior gomo-resinosa, como el de las tinajas produce los peores efectos, porque el cuero que contiene el vino sufre el calor de la mula que lo lleva en los lomos y del sol sumamente $\operatorname{ardoroso}^{22}$.

Uno de los problemas del vino de entonces era su escasa duración. Si se estropeaba se podía arreglar agregándole más arrope o cocido. En el sur se solía remediar la situación echándole un pedazo de carne animal a la tinaja. Gay informa al respecto que

pasado algún tiempo el vino se pone bueno, según me lo han asegurado muchas personas y se hace consumo de él conservando siempre dentro el animal ${ }^{23}$.

No es de extrañar, pues, que para disimular estos sabores era costumbre condimentar el mosto al momento de la fermentación con la adición de cáscaras de naranja o de limón, pimienta, clavo de olor, o maqui ${ }^{24}$.

Sin embargo, por la fecha a que se refiere, años 40 , ya se comenzaba a sentir la presencia de viñadores franceses. Poeppig, escribiendo en la década de 1830, cuenta de un hacendado del valle del Aconcagua que tenía "costosos barriles para producir la fermentación... a fin de obtener vinos similares a los europeos" sin perjuicio de usar también tinajas ${ }^{25}$. Por su parte, Radiguet señala que el vino se colocaba en barriles ${ }^{26}$.

\footnotetext{
20 Miers [9] II, 300; Smith [9], 103; Gay [1] II, 199.

21 Gay [1] II, 199-200.

22 Ibíd., II, 200.

23 Ibíd., II, 198-199.

24 Ibíd., II, 199.

25 Edouard Poeppig, Un testigo en la Alborada de Chile (1826-1829), Santiago, Zig-Zag, 1960, 117, citado por José del Pozo [1,] 53.

26 Haigh, Caldcleugh y Radiguet, [7], 247.
} 
Claudio Gay señala que en Chile se daba el nombre de "vinos" a los que estaban mezclados con este jarabe y que "son lo que en España se llaman licores". En cambio, el verdadero vino, sin esta adición, conservaba el nombre de "mosto":

Esta bebida es la que merece verdaderamente el nombre de vino, porque se fabrica en todo como los vinos de Europa. Hasta hace pocos años lo fabricaban casi solo en las provincias situadas al sur del Maule... ${ }^{27}$

Además de la ausencia de arrope o cocido, el mosto se diferenciaba del vino porque también se elaboraban tintos, dejando fermentar el hollejo con el jugo de la uva. Al parecer, la mayor parte del consumo correspondía a mostos, según se desprende de las estadísticas de cabotaje nacional de la década del 50, que aún hacían el distingo entre vinos tintos, blancos y mostos.

Existía también el mosto asoleado, que se preparaba en Concepción y otras provincias,

con uvas expuestas quince o vente días al sol antes de ser pisadas. Su bondad la debe, en cierto modo, según que han sido más o menos asoleadas. Las que han permanecido veinticinco días producen un vino mejor que las que solo han estado veinte o quince, exceptuando las circunstancias especiales de la calidad ${ }^{28}$.

Para elaborar este vino, se prensaban las uvas con las manos y se echaban a una tina donde se las dejaba fermentar ocho o nueve días, al cabo de los cuales se traspasaba el líquido a tinajas. Precisamente por los costos de su elaboración los mostos asoleados tenían un mayor precio. Los mejores eran los de las haciendas de los Majuelos, las Palmas, los Maitenes del Rosal, Ranquil y Cayumanhue ${ }^{29}$.

De todos los vinos chilenos, el más logrado, al cual ya hemos hecho referencia más arriba, era el llamado moscatel, un vino para postres. Gay, que recoge los elogios de Feuillé y de Juan y Ulloa, lo describe como "de un color blanco, sonrosado, muy dulce, muy espirituoso y de un sabor muy agradable". Se fabricaba con uva blanca de Italia, que era la variedad que más se comía, y por lo mismo, se producía en poca cantidad. Estimaba la producción de este tipo en un máximo de 6 mil arrobas en $1840^{30}$.

Las otras bebidas producidas de la vid eran las chichas y el chacolí. Este último es parecido al mosto en cuanto no contiene arrope o cocido, si bien su proceso de fermentación era mucho más breve, pues ya estaba en condiciones de consumirse al cabo de seis días en la tinaja.

Esta bebida -nos dice Gay- es delgada, suave y de un sabor agridulce que la asemeja a la sidra. Su consumo es muy grande sobre todo después de la vendimia. La hay de dos clases, una blanca, fermentada sin hollejos y escobajos, y la

27 Gay [1], II, 195.

28 Ibíd., II, 197.

29 Ibíd., II, 197-198.

30 Ibíd., II, 194. 
otra morada por haberse mezclado estos hollejos y escobajos en gran abundancia al tiempo de la fermentación ${ }^{31}$.

Por la falta de azúcar y taninos, el chacolí se deterioraba al cabo de cinco o seis meses. Sin embargo, su calidad podía ser excelente como era el que elaboraba Joaquín Tocornal en su viñedo cerca de Ñuñoa y que producía 5.300 arrobas con 25.00 plantas $^{32}$.

\section{LA NUEVA VITIVINICULTURA}

La renovación de los vinos chilenos comenzó por la introducción de nuevas cepas que se sumaban a la "uva país", la moscatel y las otras variedades existentes, ya mencionadas. Tradicionalmente se ha considerado a Silvestre Ochagavía como el iniciador de esta renovación vitivinícola chilena. Luis Correa Vergara señala que Ochagavía introdujo diversas variedades de cepas francesas en 1851 y trajo también a un viticultor francés de apellido Beltrán para cuidar los sarmientos ${ }^{33}$. Sin embargo, José del Pozo señala que esta modernización había sido iniciada en el decenio anterior por algunos franceses y que la Quinta Normal tenía estas nuevas variedades ya en la década de $1830^{34}$.

Claudio Gay, cuyas últimas observaciones in situ datan de 1841, declara que el viñedo del "Mariscal" de Manuel Antonio Tocornal tenía cien mil plantas de diversas variedades siendo las principales

el cavernet [sic] sauvignon colorado y blanco de Burdeos, el Malbec negro, el pinot colorado y blanco de Borgoña y el pinot rosado-blanquisto, variedad... cuyo vino es excelente, el gamet, el Chasselas de Fontainbleau para la mesa y el chasselas colorado que es de mejor conservación ${ }^{35}$.

Otro intento temprano, pero posterior a Ochagavía, parece haber sido la viña de los religiosos del Sagrado Corazón en el fundo Los Perales de Quilpué, adquirido a comienzos de la década de $1850^{36}$. Edmond R. Smith, escribiendo por este tiempo, observa los cambios que se estaban produciendo, pero se mostraba poco optimista respecto del futuro:

Unos pocos extranjeros han emprendido la fabricación de vinos finos en el país pero nunca en una escala lo suficientemente extensiva para ejercer alguna influencia benéfica; y aunque sus ventajas en el cultivo de la uva son quizás

31 Ibíd., II, 193-194.

32 Ibíd.

33 Luis Correa Vergara, Agricultura Chilena, Santiago, Imprenta Nascimento, 1938, II, 256-257; "Efemeridas", en Boletín de la Sociedad Nacional de Agricultura (en adelante BSNA), Vol. XIII, N 7 , 20-1-1882, 144.

34 Del Pozo [1], 70.

35 Gay [1], II. 205.

36 Raúl Besoaín Armijo, 150 años de Historia del Colegio de los Sagrados Corazones del Arzobispado de Santiago, Santiago Colegio de los Sagrados Corazones, Impresos JET, 2000, 24-29. Agradezco esta referencia al profesor Matías Tagle. 
insuperables, pasarán muchos años antes que Chile pueda entrar en el mercado en competencia con los países productores de vino del Viejo Mundo ${ }^{37}$.

Uno de los viñateros más importantes de este nuevo ciclo fue José Tomás Urmeneta que plantó en su viña de Limache 115.000 sarmientos de cepas pinot, cot, cabernet y gamet para los tintos, y semillón, moscatel y sauvignon para blancos. Un informe de 1869 señala que, en un comienzo, dicha viña no prestó demasiado cuidado a la selección de las cepas pero que en los últimos años se había dado particular interés al cabernet y gamet para los tintos y al pinot blanc y la blanquette para los blancos ${ }^{38}$. En la viña Panquehue formada por Maximiano Errázuriz en la década de 1870, tanto los sarmientos como los técnicos franceses para su cultivo provenían de la viña de su suegro Urmeneta en Limache ${ }^{39}$. La viña Santa Ana formada por Francisco Undurraga en Talagante fue plantada con pinot y cabernet, y cepas alemanas, presumiblemente riesling, adquiridas en Bonn, Francfort, Coblenza y Colonia durante el viaje que hizo el propietario en calidad de secretario del barón de Porto Seguro al Congreso Estadístico de Estocolmo en los años $70^{40}$. Otros viñateros, como Ossa y Subercaseaux, también importaron sarmientos de Europa e incluso algunos trajeron cepas de Madeira ${ }^{41}$.

El desarrollo de las viñas obedece a sólidos motivos económicos. Conforme a la investigación de Horacio Aránguiz y Cristián Rodríguez sobre el valle del Aconcagua, una cuadra plantada con trigo en 1874 producía un ingreso de 75 pesos al año en Los Andes y 90 pesos en San Felipe; una cuadra de viña en la misma zona y año producía:

$\begin{array}{lccc} & \text { Chacoli } & \text { Chicha } & \text { Mosto } \\ \text { San Felipe } & 812 & 928 & 1.392 \\ \text { Los Andes } & 696 & 928 & 1.856\end{array}$

No es de extrañar, pues, que los propietarios locales se abocaran a plantar viñas y construir bodegas, o dieran sus tierras en arriendo con el compromiso de que los arrendatarios hicieran lo mismo, como hicieron Isabel Caces de Brown y Nicolás Novoa, en Panquehue ${ }^{42}$. La misma idea sobre las ventajas de una viña moderna la encontramos en la monografía de Aurelio Fernández sobre el fundo Esmeralda de Melipilla perteneciente a su padre ${ }^{43}$

37 Smith [9], 103.

38 Ricardo Nazer Ahumada, José Tomás Urmeneta. Un empresario del siglo XIX, Santiago, DIBAM 1994, 212, citado en Del Pozo [1], 82; Marin Pescheux, "Exposición sobre el cultivo de la viña en la hacienda de Limache y sus productos", BSNA Vol. I, 1869, 171-172.

39 Carmen Valle [Blanca Subercaseaux Errázuriz], Don Maximiano, Santiago, Editorial Alonso Ovalle, 1954, 164

40 Francisco R. Undurraga V., Recuerdos de ochenta años (1855-1943), Santiago, Imprenta El Imparcial, 1943, 102-106.

41 "Revista vinícola", BSNA Vol. XII, No 12, 5-4-1881, 230-233.

42 Horacio Aránguiz Donoso y Cristián Rodríguez Salas, "Tradicionalismo y cambio agrícola en Aconcagua: elementos para su comprensión”, Historia Vol. 29, 1995-1996, 29-33. Agradezco al profesor Aránguiz esta referencia y la siguiente,

43 Aurelio Fernández Jara-Quemada, Monografía agrícola del Fundo La Esmeralda. Memoria presentada para optar al título de Ingeniero Agrícola, Santiago, Imprenta Victoria 1885, 190-203 y 379. 
El enólogo Manuel Rojas en su Tratado de Viticultura y Vinificación de 1897 entrega una nómina de las distintas variedades de uva europeas y americanas agregando una referencia sobre su difusión en Chile. A partir de la anterior, y de un estudio del mismo autor sobre diferentes viñas, se ha elaborado el siguiente cuadro que se limita a las cepas que tenían alguna presencia en el país y excluye aquellas de las que solo existían muestras o ejemplares aislados. La mayor parte de estas 41 cepas era de introducción reciente, y es muy probable que detrás de estos nombres se hayan escondido otras variedades, como lo insinúa el descubrimiento de la existencia en Chile del carménère que no figura en esta lista ${ }^{44}$.

\section{CUADRO $N^{\circ} 1$}

\section{VARIEDADES DE VIDES EXISTENTES EN LOS VIÑEDOS DE CHILE HACIA 1897}

\begin{tabular}{|c|c|c|}
\hline Variedad & Color & Frecuencia \\
\hline Blanqueta o clareta & blanca & Existe en algunas viñas \\
\hline Chasselas dorado & blanca & Hay en muchas partes \\
\hline Gamet blanco & blanca & Hay en muchas partes \\
\hline Listán Blanco o Palomino & blanca & Existe \\
\hline Italia & blanca & No figura en lista pero sí en varias viñas \\
\hline Loca blanca & blanca & Hay bastante \\
\hline Meslier & blanca & Existe en poca cantidad \\
\hline Moscatel blanco común & blanca & Existe \\
\hline Moscatel de Alejandría & blanca & Hay bastante \\
\hline Pinot blanco Chardonnay & blanca & Hay en muchas partes \\
\hline Pinot blanco verdadero & blanca & Hay \\
\hline Riesling & blanca & Algunos viñedos la poseen en gran cantidad \\
\hline Sauvignon blanco & blanca & Algunos viñedos la tienen en buena cantidad \\
\hline Semillón blanco & blanca & Hay en bastante abundancia por todas partes \\
\hline Torrontés & blanca & Muchas viñas ya la tienen en buena cantidad \\
\hline Moscatel violeta (uva pastilla) & rosada & Existe (se usa para pisco) \\
\hline Moscatel rojo de Madera & rosada & Existe poco \\
\hline Aramón & negra & Existe en algunas grandes viñas del sur. \\
\hline Cabernet & negra & La cepa francesa más abundante en Chile \\
\hline Cabernet- sauvignon & negra & Hay en mucho viñedos y en bastante cantidad \\
\hline Gamet de Orleáns & negra & Hay mucho \\
\hline Gamet negro o Petit Gamet & negra & Hay bastante \\
\hline Grappu (Saint Emilion) & negra & Existe en muchos viñedos chilenos \\
\hline Italia moscatel & negra & No figura en lista pero sí en varias viñas \\
\hline Malbec o Côt rouge & negra & La cepa más corriente después del Cabernet \\
\hline Mansenc & negra & Hay en algunas viñas en cierta proporción. \\
\hline Merlot & negra & Muy abundante \\
\hline Meunier o molinero (Morillon) & negra & Hay en poca cantidad \\
\hline Moscatel negro & negra & Muy abundante \\
\hline País o uva común & negra & La cepa que domina en Chile \\
\hline Petit Bouschet (híbrido) & negra & Existe en algunas grandes viñas del sur. \\
\hline Pignon o Sauvignon negro & negra & [No figura en lista pero sí en viña Chaigneau] \\
\hline Pinot gris & negra & Algunos viñedos la tienen en buena cantidad \\
\hline
\end{tabular}

44 Rojas [2], 44-83 y 97-118. Sobre el "descubrimiento" del carménère y la identificación incorrecta de otras variedades véase Philippo Pszczólkowski, "La invención del cv. Carménère (vitis vinifera L.) en Chile, desde la mirada de uno de sus actores", Universum (Talca) N 19, Vol. 2, 2004, 150-165. 


\begin{tabular}{lll}
\hline Variedad & Color & Frecuencia \\
\hline Pinot negro & negra & Hay en todos los viñedos franceses de Chile \\
Romano o césar & negra & Hay en muchos viñedos chilenos \\
San Francisco & negra & Hay en todas partes \\
Syrah & negra & Escaso \\
Tintorero hembra & negra & Hay en poca cantidad \\
Tintorero macho & negra & Hay en poca cantidad \\
Tressot & negra & Hay en cierta cantidad \\
Verdot & negra & Hay solo en algunos viñedos \\
\hline
\end{tabular}

Fuente: Manuel Rojas L., Tratado de viticultura y vinificación (Segunda edición), Santiago, Imprenta y Encuadernación Barcelona, 1897, 44-83.

La proporción de cepas francesas aumentó durante los años 70. A comienzos de 1882 un articulista en el Boletín de la Sociedad Nacional de Agricultura declaraba que estas "ocupaban dos tercios de las viñas de todo el país" 45 . Sin embargo, hay razones para pensar que la afirmación obedecía más a un deseo que a la realidad. La uva país seguía siendo la más difundida, y otras variedades como la San Francisco o la Italia también se encontraban por doquier. Solo tres cepas nuevas tenían alguna difusión: el cabernet y el pinot usado para fabricar vinos de tipo burdeos y borgoña, respectivamente, y el semillón blanco para los sauternes ${ }^{46}$. Estas cepas se usaban puras o en combinaciones según su calidad. Manuel Rojas indica las proporciones que se debían emplear, siguiendo probablemente algún modelo francés; sin embargo, es más que probable que en Chile se usara también la uva país u otras variedades para los tipos de menor calidad, siendo que los rendimientos de las cepas de menor jerarquía que se recomendaban para las mezclas no eran tales que permitieran una reducción significativa de $\operatorname{los} \operatorname{costos}^{47}$.

\section{CUADRO $\mathrm{N}^{\circ} 2$}

\section{PROPORCIONES PARA COUPAGES SEGÚN MANUEL ROJAS}

\begin{tabular}{|c|c|}
\hline Burdeos tinto de $1^{\mathrm{a}}$ clase & Cabernet Sauvignon, o Cabernet puro \\
\hline Burdeos tinto de $2^{\text {a }}$ clase & $\begin{array}{l}\text { Cabernet o Cabernet Sauvignon (50\%); Verdot } 25 \% \text {, Malbec o Merlot } \\
(25 \%)\end{array}$ \\
\hline Burdeos tinto de $3^{\text {a }}$ clase & Cabernet o Cabernet Sauvignon (25\%); Malbec o Merlot (75\%) \\
\hline Sauterne (Burdeos bco.) $1^{\mathrm{a}}$ clase & Semillón blanco (70\%); Sauvignon blanco $(30 \%)$ \\
\hline Sauterne (Burdeos bco.) $2^{\mathrm{a}}$ clase & Semillón o Sauvignon (50\%), Blanqueta (50\%) \\
\hline Borgoña tinto de $1^{\mathrm{a}}$ clase & Pinto negro, puro \\
\hline Borgoña tinto de $2^{\mathrm{a}}$ clase & Pinot negro (50\%); Romano (25\%), Tressot $(25 \%)$ \\
\hline Borgoña tinto de $3^{\mathrm{a}}$ clase & Pinto negro (25\%), Romano o Tressot (25\%) y Gamet negro (50\%) \\
\hline Borgoña Blanco de $1^{\mathrm{a}}$ clase & Pinot blanco puro \\
\hline Borgoña Blanco de $2^{\mathrm{a}}$ clase & Pinot blanco $(50 \%)$, Gamet blanco $(50 \%)$ \\
\hline Rhin & Riesling puro 48 \\
\hline
\end{tabular}

45 "Efemérides" [32], 144

46 Véanse, por ejemplo, los anuncios en El Independiente, 17-8-1883 p. 3 col 7; íd., 18-8-1883; Almanaque Comercial para el año de 1884, Valparaíso, Imprenta de La Patria, 1883, 57, 136.

47 La lista de rendimientos por cepa en Manuel Rojas [2], 279.

48 Rojas [2], 93-96. 
La introducción de nuevas cepas, empero, no bastaba para tener un vino a la francesa. Hay que tener presente que estas nuevas viñas requerían de fuertes inversiones no solo para los plantíos y el cuidado hasta su entrada en producción, sino también para la elaboración del vino. José del Pozo ha estudiado la introducción de maquinaria moderna, primero de procedencia extranjera y luego de fabricación local entre los viñateros y productores, y no es del caso volver sobre ello ${ }^{49}$. Una idea del grado de mecanización la da William H. Russell que acompañó a John Thomas North en su visita a la viña de Isidora Goyenechea de Cousiño, en Macul, al tiempo de la cosecha. Quedó impresionado por el "enorme terreno, un mar de vides atravesado por surcos por los que escurría agua cristalina -donde hombres y mujeres estaban ocupados cargando grandes cantidades de uva a los vagones sobre rieles que las llevarían desde los campos hasta las prensas de los lagares" ${ }^{20}$. Otra descripción de la viña en esa misma visita agrega:

Las cepas son todas de origen francés. Las principales son el cabernet sauvignon, de importancia en las históricas viñas de Medoc, el pinot de Borgoña, el merlan, el malbec, el verdau, y el semillón blanc. Las viñas crecen con espalderas, de acuerdo con el método preferido hoy en algunos de los departamentos más adelantados de Francia con el apoyo de tres hebras de alambre estiradas entre postes de hierro, lo que elimina la necesidad de estacas. Las melgas están a una distancia de unos cuatro pies seis pulgadas [1,37 mts.] y la misma separación se deja entre todas las plantas. El sistema de cultivo es, en general, el que ahora se emplea en la región de Burdeos. Sin embargo, por las particularidades del clima de Chile ha sido preciso instalar riego artificial. A lo largo de las melgas se cavan acequias comunicadas con tranques, desde los cuales se deja salir el agua en ciertas épocas, en especial cuando la uva comienza a formarse. Las vides producen al tercer año y se les deja dos brotes a cada lado del tronco ${ }^{51}$.

El crecimiento de las viñas, la necesidad de un recinto que reuniera las condiciones adecuadas para la elaboración, fermentación y en especial el proceso de envejecimiento del vino, exigía la construcción de bodegas especiales de gran tamaño y con equipamiento moderno. El citado visitante a la viña Macul agrega a su descripción.

Las uvas se limpian y se prensan a máquina en lugar de pisarlas. Se deja el mosto junto con las uvas prensadas por cuatro o cinco días, luego se trasvasija a pipas donde permanece durante tres meses. Se trasvasija nuevamente cuando el vino está en flor y se guarda en toneles durante tres años antes de embotellarlo. Las bodegas de Macul son frescas, espaciosas, admirablemente ventiladas y provistas de todas las instalaciones más modernas; las máquinas funcionan con vapor. Junto a la bodegas también hay una tonelería"52.

49 Del Pozo [1] 120-127.

50 William Howard Russell, A visit to the Nitrate Fields of Tarapacá, London, J.,S. Virtue, 1890, 94.

51 Museo Histórico Nacional, Reportaje a Chile. Dibujos de Melton Prior y Crónicas de The Illustrated London News, 1889-1891. [Edición bilingüe] Santiago, Fundación Andes, Museo Histórico Nacional, Montt Palumbo, editores, 1992, 48. Se ha reproducido el texto conforme al original en inglés. 52 Museo Histórico Nacional, [48], 48. Se ha ajustado el texto conforme al original en inglés. 


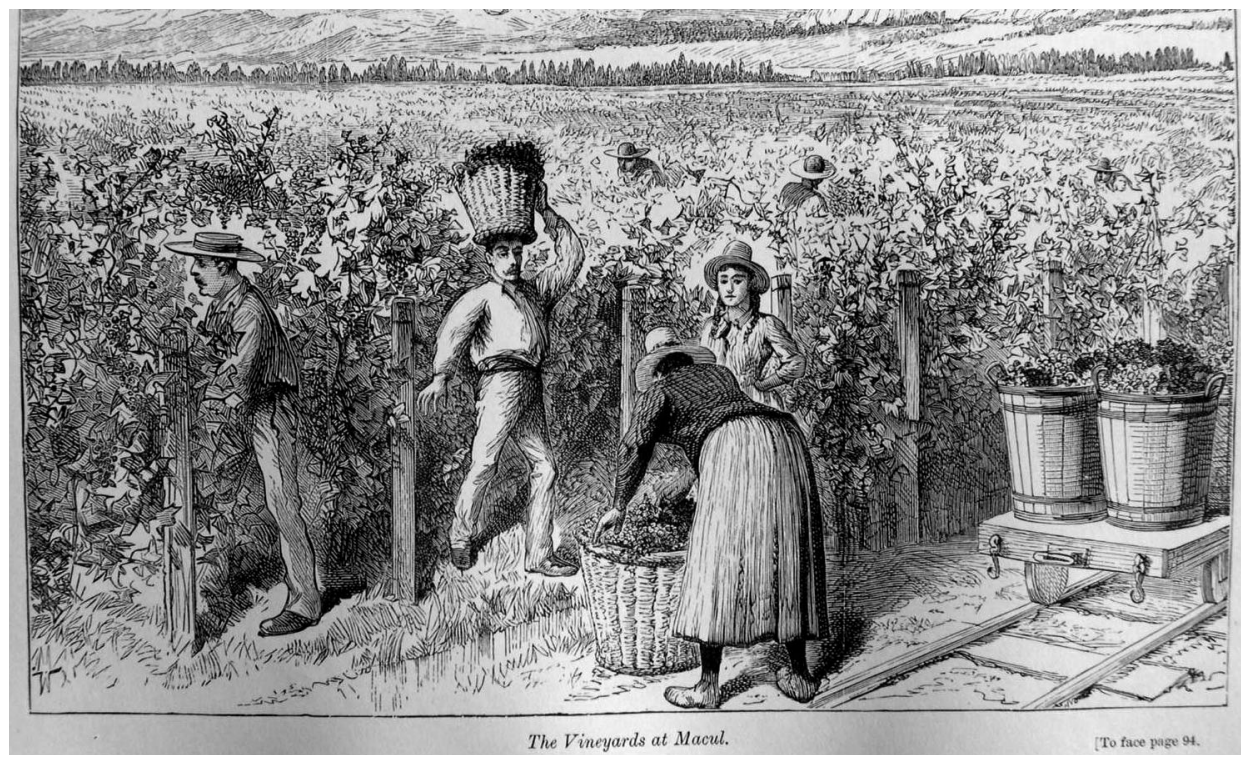

Los viñedos de Macul. Dibujo de Melton Prior. En William Howard Russell, A visit to Chile and the Nitrate Fields of Tarapacá, London, J. \& S Virtue, 1890.

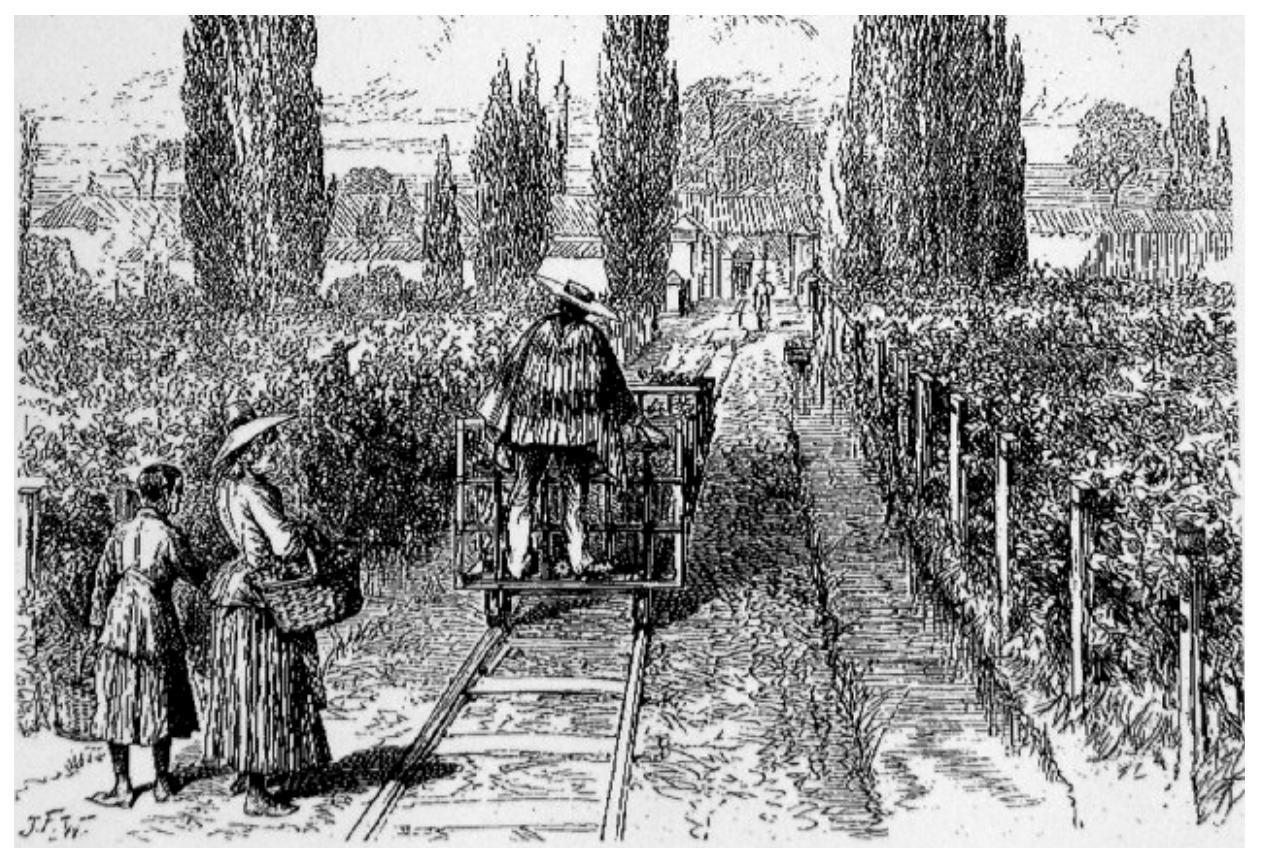

Viña Macul. Trasporte de la uva a las bodegas, Dibujo de Melton Prior, En Reportaje a Chile. Dibujos de Melton Prior y crónicas del Illustrated London News 1889-1891, Santiago, Fundación Andes, Museo Histórico Nacional, Montt Palumbo, editores, 1992. 
Las principales viñas tenían instalaciones semejantes. En la viña Santa Carolina, Luis Pereira había construido las bodegas en 1877, las cuales fueron ampliadas sucesivamente en 1888 y 1898. Las de la viña Urmeneta databan de 1870 y habían sido objeto de sucesivas ampliaciones. También en la Viña Concha y Toro hubo que construir nuevas bodegas durante el siglo $\mathrm{XIX}^{53}$.

Conforme a las descripciones de Manuel Rojas, las viñas chilenas fermentaban sus vinos tintos en cubas de albañilería o de madera, abiertas o cerradas, por tiempos que iban desde cuatro hasta 30 días. Los periodos más breves correspondían a la viña Subercaseaux y el más prolongado a la de Macul. En Chillán, las viñas fermentaban los vinos entre seis y 12 días y en Concepción de 10 a $14^{54}$. Un elemento central de las nuevas técnicas francesas era la fermentación en vasijas de madera. En Panquehue el mosto recién exprimido pasaba a los fudres, dos de los cuales habían sido traídos directamente de Burdeos, que reposaban en frescas bodegas. En la viña Undurraga las vasijas las hizo un tonelero francés a partir de unas duelas de roble de Bosnia y Herzegovina en que venían acuñados unos vagones y locomotoras para los Ferrocarriles del Estado. En otros casos, las cubas y toneles eran adquiridos a las tonelerías locales como aquellas instaladas en Concepción, Melipilla, San Fernando, Coelemu, Chillán y otras ciudades ${ }^{55}$. Seguidamente, venía el vaciado de las cubas, el filtrado del vino, el prensado del orujo y, para los vinos ordinarios, la adición de este "vino de prensa", más amargo, al anterior vino de gota", en proporciones determinadas. De ahí el producto pasaba a los toneles -fudres, pipas o barricas, de distintos tamaños- siendo objeto de posterior trasiego o decantación hasta quedar listo para su embotellado ${ }^{56}$. Señala Manuel Rojas que los vinos comunes se vendían en el año de la cosecha y a granel; en cambio los vinos finos eran embotellados después de un proceso de maduración en barricas. En la viña Panquehue los vinos finos se guardaban por cuatro años, más otros tres en la botella. En la viña Subercaseaux los vinos se embotellaban a los tres o cuatro años con seis meses en botella; en el caso de la viña Santa Carolina los tiempos eran de tres años para el pinot y cuatro para el cabernet, más un año en botella, mientras que en la viña Macul los vinos tenían tres años al envasar y una guarda adicional de ocho meses en botella ${ }^{57}$. El producto resultante era muy distinto al vino tradicional que difícilmente se conservaba de un año al otro.

La Exposición Nacional de Agricultura de 1869 sirvió para mostrar los avances logrados en la materia, Junto con mostos dulces, chacolí y vinos moscateles se exhibieron varias muestras de "imitación de Burdeos". Entre los expositores estaba Juan Duprat, quien presentó vinos de San Francisco de Limache hechos en 1863, 1864, 1865, 1866, 1867 y 1868, mientras Francisco Subercaseaux de Santiago lo

53 Oscar Ortega y otros, Guía de la arquitectura de Santiago, Facultad de Arquitectura y Urbanismo, Universidad de Chile, Santiago, 1976. 160-161; Luis Navarro y Cía. (eds.). Album de las ferias municipales y matadero. Guía agrícola de las Provincias de Santiago, Colchagua y Aconcagua, Santiago, Imprenta y Litografía "La Ilustración”, 1931, 154. Agradezco esta referencia al profesor Horacio Aránguiz.

54 Rojas [2], 302-320.

55 Del Pozo [1], 124-125; Undurraga [39], 104-105.

56 Rojas [2], 320-348.

57 Rojas [2], 370. 


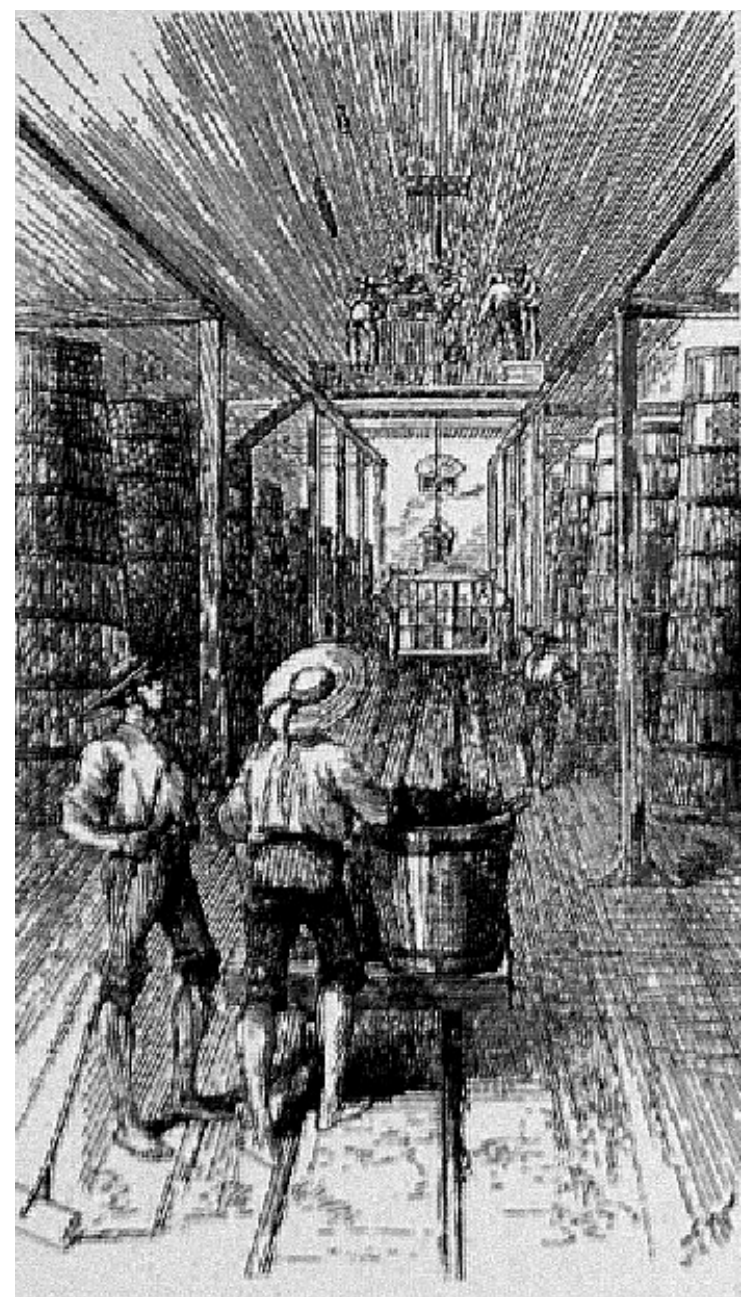

Viña Macul. Entrada a la bodega. Dibujo de Melton Prior. En Reportaje a Chile. Dibujos de Melton Prior y crónicas del Illustrated London News 1889-1891, Santiago, Fundación Andes, Museo Histórico Nacional, Montt Palumbo, editores, 1992.

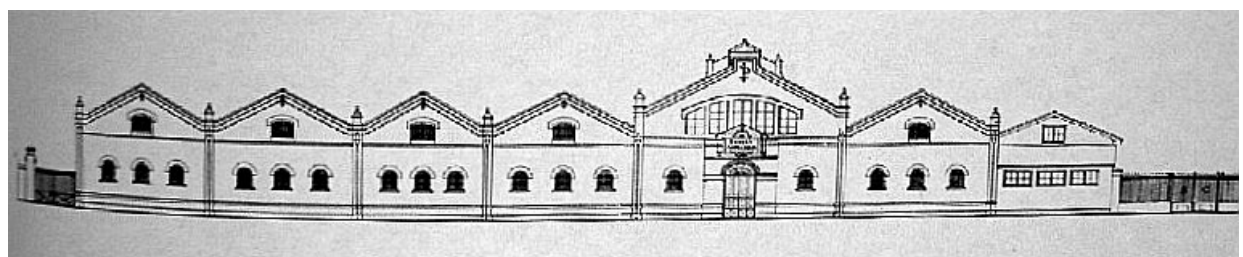

Bodegas de la viña Santa Carolina, fachada. En Óscar Ortega S. y otros, Guía de la arquitectura en Santiago, Santiago, Universidad de Chile, Facultad de Arquitectura y Urbanismo, 1976, 
hizo con tintos y blancos de su viña, de cosechas años 1865, 1866, 1867 y 1868. De este modo se enfatizaba la duración que podía tener el producto ${ }^{58}$.

Los vinos se anunciaban tanto conforme a las cepas como a su tipo: burdeos, borgoña, sauternes, rhin, jerez y, más tarde, champagne. Por lo general se advierte al consumidor que se trata de vinos "tipo burdeos" o "tipo jerez", si bien con el tiempo se pasará a anunciar el producto sencillamente como champagne o jerez. Esta identificación con el referente europeo también se dio en el caso de Argentina, según lo ha estudiado Pablo Lacoste ${ }^{59}$.

\section{LAS CIFRAS DE PRODUCCIÓN}

Las estadísticas de producción agrícola elaboradas a partir de la década de 1860, y que incluyen la fabricación de vinos y mostos, aguardiente, chicha y chacolí, presentan notorias deficiencias como lo reconocían las mismas autoridades de la época. En algunos años, la información recogida es manifiestamente incompleta; en otros, la autoridad local no envió la información requerida y hubo ocasiones en que las estadísticas sencillamente no se publicaron. En vista de lo anterior, las cifras proporcionadas deben ser tomadas con cautela. Sin perjuicio de esta advertencia, es posible obtener algunas conclusiones. Dado que los datos se entregan por departamento y por provincia, es posible efectuar la extrapolación a estos niveles, para aprovechar así los datos sueltos y aminorar las distorsiones en las series. Por otra parte, la información desagregada permite apreciar el distinto desarrollo que tuvo la producción de vinos en las diferentes provincias. Tradicionalmente, la mayor parte de la producción de vino provenía de las tierras al sur del río Maule. Conforme a las estadísticas mencionadas, las provincias de Linares, Maule, Ñuble, Biobío y Concepción representaban más del 80 por ciento de la producción chilena en el quinquenio 1861-1865. Sin embargo, a partir de entonces la zona centro norte va adquiriendo creciente importancia; a comienzos del siglo XX la proporción de las mencionadas provincias había bajado a menos del 70 por ciento y para el quinquenio 1916-1920 llegaba al 54 por ciento.

Este desarrollo está directamente relacionado con la renovación de la viticultura chilena. En efecto, un reconocimiento de la extensión que había alcanzado la técnica francesa en la producción de vinos es la incorporación de las cifras de producción de "burdeos" -es decir, de vinos de cepa y tecnología francesa a imitación de los burdeos- en el Anuario Estadístico de la República de Chile como rubro aparte. En 1870 , un año después que se inicia la serie de producción de vino imitación burdeos, la principal zona productora era Santiago y específicamente los departamentos de Santiago y La Victoria (Puente Alto). En orden de magnitudes seguían los departamentos de Los Andes, San Fernando, Quillota e Illapel.

58 Catálogo oficial de la exposición de Agricultura inaugurada solemnemente en Santiago el 5 de mayo de 1869, Valparaíso, Imprenta del Mercurio, 1869, 164-172.

59 Pablo Lacoste, El vino del Inmigrante, Mendoza, Universidad del Congreso, Consejo Empresario Mendocino, 2003, 115.219. 


\section{GRÁFICO Nº 1}

PRODUCCIÓN DE VINOS POR REGIONES Y QUINQUENIOS, 1861-1920

MILES DE LITROS PROMEDIO ANUAL

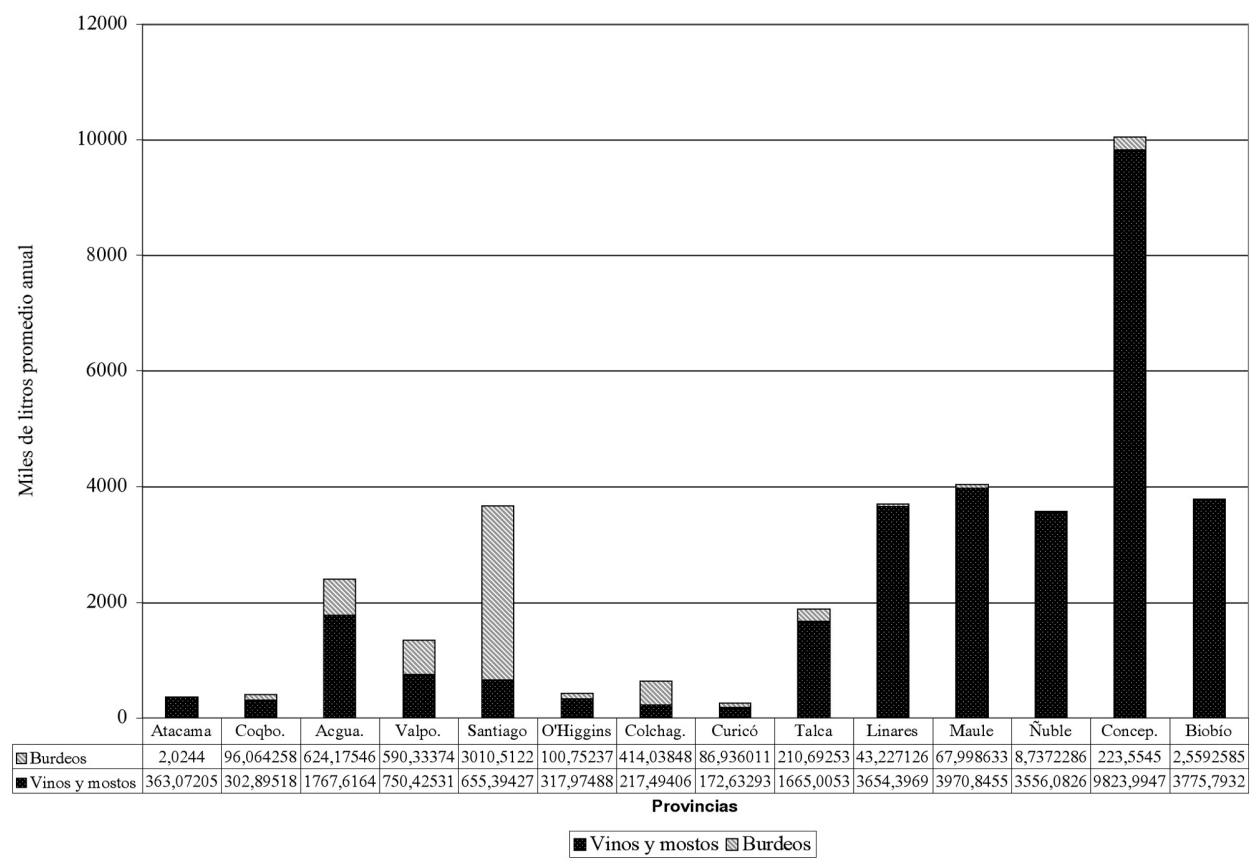

Fuente: Anuario Estadístico de la República de Chile 1861-1875. Las cifras por provincia están calculadas sumando las producciones de los departamentos correspondientes.

Con todo, la producción de "burdeos" era aún muy limitada y durante el quinquenio 1871-1875 representaba apenas el 5,5 por ciento del total de vinos. La producción se concentraba en la provincia de Santiago, que representaba dos tercios del total. La distribución por regiones era como lo indica el Gráfico 2.

Diez años más tarde, en el quinquenio 1881-1885, el "burdeos" representaba el 15 por ciento del total de vinos.

Comparando los Gráficos 2 y 3 se aprecia una extensión de las nuevas cepas francesas. En el curso de una década se fueron sumando otras zonas: San Felipe en Aconcagua, Limache y Casablanca en Valparaíso, Rengo (el depto. de Caupolicán) en Colchagua, Curicó, la provincia de Talca y especialmente el departamento de Coelemu en Concepción, que concentraba la casi totalidad de la producción de vinos a la francesa en la provincia. 


\section{GRÁFICO $\mathrm{N}^{\circ} 2$}

PRODUCCIÓN DE VINOS Y “BURDEOS” POR PROVINCIA, 1871-1875

MILES DE LITROS PROMEDIO ANUAL

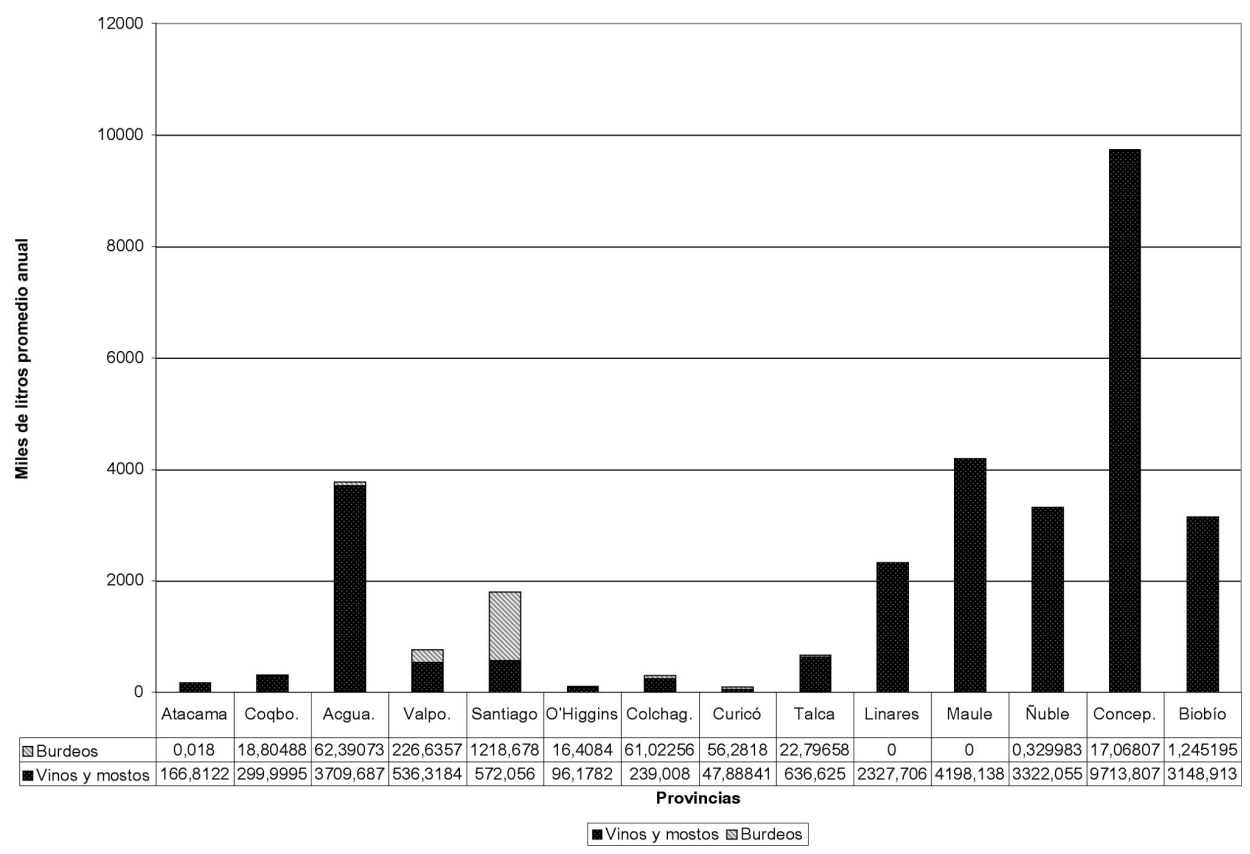

Fuente: Anuario Estadístico de la República de Chile 1871-1875.

A partir de 1885, la distinción de vinos de tipo burdeos desaparece de las estadísticas y su producción se integra a la de vinos y mostos. Este cambio se explicaría por la difusión de las cepas francesas, que hacía difícil, cuando no irrelevante, mantener la diferenciación anterior. A comienzos de 1882 un articulista en el Boletín de la Sociedad Nacional de Agricultura llegó a declarar que estas "ocupaban dos tercios de las viñas de todo el país". ${ }^{60} \mathrm{Su}$ entusiasmo parece exagerado. Manuel Rojas entrega una lista de 34 viñas en distintas regiones del país, indicando, en 27 casos, las cepas cultivadas y el número de vides de cada variedad. La muestra está evidentemente sesgada a favor de las cepas francesas, pues, conforme a sus propósitos, el autor se concentra en las viñas más importantes y progresistas del país, que son las que tienden a introducir las nuevas variedades. Sin embargo, los resultados de la misma confirman las tendencias ya observadas. En las 18 viñas entre los departamentos de La Ligua y Talca, mencionadas por Rojas, más del 99 por ciento de las vides eran de cepas nuevas. En cambio en las siete

60 "Efemérides" [32], 144. 
restantes la proporción llega al 30 por ciento ${ }^{61}$. Ahora bien, si aplicamos los porcentajes de esta muestra a la producción total para 1897, distinguiendo entre las respectivas zonas (30 por ciento de la producción al norte del Maule y 70 por ciento al sur del mismo), resulta que el 57 por ciento de las vides de Chile eran de variedades tradicionales, especialmente uva país. Otro testimonio relativo al departamento de Melipilla avala la idea que la modernización iba más lenta de lo que se afirma. Escribiendo a mediados de los años 80, el agrónomo Aurelio Fernández señala

Los que lo cultivan con mayor preferencia son, por lo general, muchas personas poco pudientes que carecen tanto de recursos como de conocimientos científicos adecuados al caso.

\section{GRÁFICO N³}

PRODUCCIÓN DE VINOS Y “BURDEOS” POR PROVINCIA, 1881-1885

MILES DE LITROS PROMEDIO ANUAL

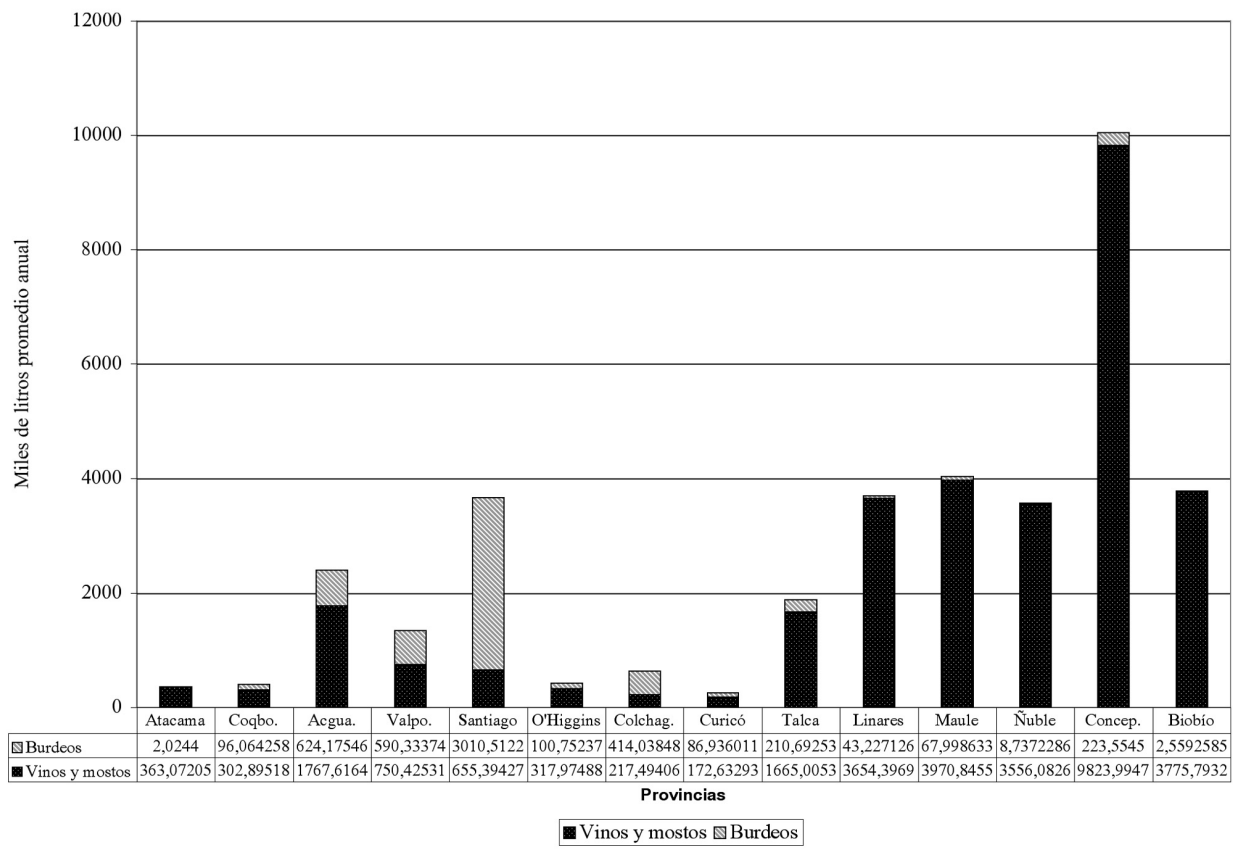

Fuente: Anuario Estadístico de la República de Chile 1881-1885.

61 Rojas [2], 93-118. 
La mayor parte de las viñas que en esta región se encuentran son del país y de cabezas.

Sin embargo, parece que la suerte de la vinicultura local habrá de recibir en tiempo no lejano una transformación favorable, a juzgar por la introducción de viñas francesas que se ha hecho en algunos parajes en los últimos años ${ }^{62}$.

\section{LA CALIDAD}

El resultado de la introducción de las técnicas francesas fue una mejoría en la calidad de los vinos chilenos, los que podían rivalizar con los importados. Cuando Carlos Segundo Lambert visitó la hacienda Culiprán en 1881 para comprar la propiedad, su anfitrión, Ladislao Larraín, le ofreció una "excelente comida bajada con buen vino de Limache" 63 . El ya mencionado William Howard Russell también elogió a los vinos chilenos:

Los vinos del país son tan buenos que no es de extrañar que los naturales beban casi todo lo que se produce y dejan muy poco de las mejores cosechas de Urmeneta, Macul y Paquerete [¿Panquehue o pajarete?] para la exportación. Los de mejor calidad no son baratos... ${ }^{64}$.

Para fines del siglo XIX, los vinos chilenos de marca eran lo suficientemente buenos para ser bebidos por aquellos que estaban en situación de tomar de lo mejor. Resulta significativo que en vísperas de su reunión con el Presidente Julio A. Roca en Punta Arenas, el Presidente Errázuriz Echaurren escribía a su primo Rafael Errázuriz Urmeneta solicitándole tres cajones de vino tinto y tres cajones de vino blanco de su viña para obsequiarlos al mandatario argentino ${ }^{65}$. También es interesante constatar que, según una guía de Lima para 1876, los vinos Subercaseaux blanco y tinto eran exportados al Perú y vendidos bajo esa marca, donde competían con los vinos peruanos y los propios franceses ${ }^{66}$.

Otro reconocimiento más formal de la calidad de los vinos chilenos proviene de las medallas obtenidas en sucesivas exposiciones internacionales. La concurrencia a estos torneos no era fácil. Las muestras enviadas a la Exposición Universal de Viena de 1877 llegaron a esa ciudad un día después que el jurado se había disuelto, si bien los vinos fueron alabados en un banquete oficial posterior ${ }^{67}$. Mejor suerte

62 Fernández Jara-Quemada, [42], 189.

63 Gerald Young, (ed.) The Voyage of the "Wanderer". From the journals and letters of C and $S$ Lambert, London, Macmillan and Co. 1883, 127.

64 Russell [47]. 144.

65 Federico Errázuriz Echaurren a Rafael Errázuriz Urmeneta, 21-1-1899, AREU Vol. 15, Fs 147, citado por Ricardo Nazer, Historia de dos familias de la elite chilena: Errázuriz Urmeneta y Edwards Mac Clure, 1840-1940, borrador inédito, Segunda parte, Cap 3.3.

66 Citado por Margarita Guerra Martiniere, La Ocupación de Lima (1881-1883) Aspectos económicos del Gobierno de García Calderón, Tomo II, Lima, Pontificia Universidad Católica del Perú, 1996, 42 y Cuadro 2 frente a 48.

67 Julio Menadier, "Las ciruelas secas", BSNA, Vol. XVII, N² 21 , agosto 1886, 466-468. 
tuvo la vitivinicultura nacional en la exposición de Burdeos de 1883. Apoyados por la Sociedad Nacional de Agricultura, concurrieron 30 expositores nacionales que obtuvieron en su conjunto cuatro medallas de oro, siete de plata, siete de bronce y cinco menciones honrosas ${ }^{68}$. Un éxito parecido obtuvieron los vinos chilenos enviados por la misma Sociedad a una exposición en Liverpool en 1886. En esa oportunidad 14 vinos, nueve tintos y cinco blancos, lograron medalla de oro; 12 vinos, cinco tintos y siete blancos, obtuvieron plata; además se lograron cuatro medallas de bronce y una mención honrosa ${ }^{69}$. Entre 1869 y 1901 la viña Urmeneta de Limache había obtenido premios y medallas de oro y plata en once exposiciones internacionales y nacionales ${ }^{70}$.

Con todo, la elaboración de vinos, especialmente en el sur, aún presentaba deficiencias. Un artículo en el Boletín de la Sociedad Nacional de Agricultura publicado en 1881 critica la persistencia del uso de tinajas de barro para conservar los vinos:

Para impedir la permeabilidad de estas tinajas... se las unta a menudo en el sur interiormente con una especie de brea, la que naturalmente se disuelve poco a poco y da mal gusto al líquido ${ }^{71}$.

Marco A. Reyes, refiriéndose a los vinos de Ñuble a comienzos del siglo XX, agrega que eran mal elaborados, prensados "a pata y chala limpia", y que tenían gusto a borra, pero que tenían buena demanda por su alta graduación y cuerpo, aumentado con el añadido de cepas francesas al vino país ${ }^{72}$.

La propuesta de la SNA para mejorar la calidad de estos era organizar una Sociedad Nacional de Vinicultores. Julio Menadier escribía al respecto en 1877:

Si ahora ya el mosto fabricado en las provincias de Concepción y Cauquenes, a pesar de su imperfecto sistema de elaboración, alcanza a menudo a representar perfectamente los vinos de Europa ¿qué sucedería tan luego que una sociedad oenólogo [sic] procediese a ilustrar concienzudamente... a los vinicultores nacionales las principales condiciones de una buena vinificación?...

$\mathrm{Si}$ a pesar de la inteligencia i cuidado de excelentes vinicultores franceses no se ha podido llegar a la perfección en los magníficos viñedos de Ochagavía, Urmeneta, Tocornal, Subercaseaux, Ossa, Délano, Rojas Salamanca i otros, si hai que emprender todavía allí reformas en el cultivo, la fabricación y el aprovechamiento cabal, con mayor grado se hacen sentir estas reformas en las rejiones apartadas de la Capital $^{73}$.

68 "Memoria de los trabajos ejecutados por el Directorio [de la SNA], presentada a la Junta General el 21 de octubre de 1883", BSNA Vol. XV, No 1, 20-10-1883, 1-5.

69 "Los vinos chilenos en Liverpool", BSNA Vol. XVIII, N 3, noviembre 1886, 57-58.

70 Luis Navarro y Cía (eds.). Album op. cit. 154.

71 "Revista Vinícola", BSNA Vol. XII, N 12, abril 1881, 230-233.

72 Marco Aurelio Reyes Coca, "Los vinos moscatel y país, de los cerros de Nuble: de pipeños y famas..." Tiempo y Espacio (Chillán), Nos 11-12, 2001-2002, 284-285.

73 Julio Menadier, "Sociedad Nacional de Vinicultores", BSNA, Tomo VIII, N 14, marzo 1877 , 257-260. 
Quizás el principal impedimento para la renovación de la vinicultura chilena haya sido el paladar de los consumidores que estaban acostumbrados al producto tradicional. Julio Montebruno en sus memorias recuerda que su padre (en La Serena, $c$ 1880) prefería el vino local, despreciando una barrica de vino de Siracusa que le habían regalado. "Sea porque el autor de mis días no le gustase por ser dulce, pues solo bebía el tipo chileno en las comidas, prefiriendo al embotellado el salido directamente de sus lagares, por ser sin artificios y como él decía, de pura uva..."74.

Un testimonio del sabor de estos vinos artesanales lo proporciona Manuel Rojas que entrega sus notas de cata y datos de graduación alcohólica de 22 muestras de vinos de Cauquenes ensayados en 1896; los más de ellos eran elaborados con uva común, salvo en los casos que indica. Su procedencia, agrega, la "guardamos en reserva por ser en su gran mayoría defectuosos". El cuadro siguiente reproduce los comentarios:

\section{CUADRO N${ }^{\circ} 3$}

NotAs DE CATA SOBRE VINOS DE CAUQUENES

\begin{tabular}{|c|c|c|c|}
\hline$N^{o}$ & Tipo y año & Alcohol & Comentario \\
\hline 1 & Vino de 1895 & 11,2 & Turbio, dulce y bien ácido. Fermentación mal hecha. Vino malo. \\
\hline 2 & Cabernet de vega & 13,6 & Buen vino, de porvenir \\
\hline 3 & Vino del año & 11,3 & Tinto, dulce y buen paladar; pero la mucha azúcar es un peligro \\
\hline 4 & Vino de 1893 & 13,6 & Sabor ácido, seco, delgado, apenas regular \\
\hline 5 & Vino de 1893 & 15,4 & Sin ácido, seco, pero no es sobresaliente \\
\hline 6 & Vino de 1889 & 12,9 & $\begin{array}{l}\text { Poco tinto, aromático, muy dulce, pero con cierto ácido, desagra- } \\
\text { dable }\end{array}$ \\
\hline 7 & Vino de 1891 & 15,1 & $\begin{array}{l}\text { Aromático, muy bueno. Sin el exceso de azúcar sería un verdade- } \\
\text { ro oporto }\end{array}$ \\
\hline 8 & Cabernet 1893 & 15,1 & Muy tinto y turbio; ácido; bueno sin tener bouquet \\
\hline 9 & Vino de 1890 & 13,8 & Sabor dulce, ácido y áspero. Sin la acidez sería buen oporto \\
\hline 10 & Moscatel 1894 & 18,6 & Muy aromático, seco, bueno, sin ácido. Color amarillo. \\
\hline 11 & Vino de 1892 & 14,1 & Olor bueno pero sin bouquet. Seco, ácido; no promete más \\
\hline 12 & Vino de 1895 & 15,8 & Rosado. Olor bueno; sabor seco, delgado, sin acidez \\
\hline 13 & Blanco 1895 & 13,1 & Turbio, seco, poco agradable; gusto extraño \\
\hline 14 & Moscatel 1895 & 16,0 & Algo turbio, sabor seco, sin ácido; bastante bueno \\
\hline 15 & Vino de 1893 & 15,8 & Tinto no bien depurado; seco áspero, sin ácido; bueno \\
\hline 16 & Vino de 1895 & 14,1 & Algo turbio; bien seco, sin ácido, pero un tanto amargoso \\
\hline 17 & Vino del año & 12,1 & Muy tinto y despojado; sabor de arrope con dejo amargoso \\
\hline 18 & Cabernet 1894 & 15,2 & Sabor seco, áspero, gusto de húmedo, amargoso \\
\hline 19 & Moscatel 1893 & 16,0 & Amarillento no bien claro; sabor dulce, bueno, aromático \\
\hline 20 & Semillón, 1894 & 16,5 & Amarillo no bien claro; sabor seco, sin ácido, bueno \\
\hline 21 & Vino de 1873 & 17,2 & Color y sabor propio el oporto; pero hay un dejo ácido \\
\hline 22 & $\overline{\text { Cabernet del año }}$ & 13,7 & Tinto, poco turbio; un tantito ácido, áspero, grueso \\
\hline
\end{tabular}

Manuel Rojas, Tratado de Viticultura $i$ Vinificación, segunda edición, Santiago, Imprenta y Encuadernación Barcelona, 1897, 587.

74 Julio Montebruno López, "Mi niñez y adolescencia en La Serena”, Revista Chilena de Historia y Geografía, N ${ }^{\circ} 109$, enero-junio 1947, 77. 
Conforme a estas notas, los mayores éxitos de la zona estaban en los vinos dulces, y solo una de las muestras de cabernet resultaba promisoria.

Es muy difícil saber hasta qué punto los buenos vinos chilenos alcanzaban el nivel de sus modelos franceses, no obstante las medallas y testimonios favorables antes mencionados. El ingeniero belga Gustavo Verniory cuenta haber disfrutado de un excelente almuerzo en Chillán en 1895 y agrega:

Lo regamos con una botella de "St Estephe" auténtico, cuyo precio es de cuatro pesos. Es un lujo algo tonto en un país que produce vinos que pretenden rivalizar con los de Francia, pero los vinos franceses tienen un bouquet que no alcanzan los de aquíi 75 .

Una conclusión similar se desprende del análisis y degustación de una serie de muestras de vinos chilenos enviados a la Exposición Universal de París de 1889, efectuada por el director del Laboratorio Municipal de la ciudad M. Girard con los resultados que siguen:

\section{CUADRO $\mathrm{N}^{\circ} 4$}

ANÁLisis DE VINOS CHILENOS EN PARÍs, 1889

\begin{tabular}{lllll}
\hline Vino & $\begin{array}{l}\text { Propietario } \\
\text { de viña }\end{array}$ & $\begin{array}{l}\text { Alcohol } \\
\text { \% en } \\
\text { volumen }\end{array}$ & $\begin{array}{l}\text { Acidez } \\
\text { en SO } \mathrm{SO}_{3} \mathrm{HO} \\
\text { por litro }\end{array}$ & Comentario textual \\
\hline Chacra Benítez, tinto 1884 & J. M. Benítez & 11.9 & 5.39 & $\begin{array}{l}\text { Añejo, correcto de gusto y bastante } \\
\text { agradable; el fruto persiste en el pa- } \\
\text { ladar, límpido, coloración amarilla, } \\
\text { bastante oscuro. }\end{array}$
\end{tabular}

Santa Carolina, tinto Luis Pereira $\quad 11.0 \quad 4.31 \quad$ Añejo, bastante finura, correcto de gusto; el fruto persiste bien en el paladar; sabor agradable; bueno.

\begin{tabular}{|c|c|c|c|c|}
\hline Chacra Victoria, tinto 1887 & M. J. Díaz & 12.7 & 4.65 & $\begin{array}{l}\text { Gusto correcto, fruto persistente, } \\
\text { bastante finura y agradable. }\end{array}$ \\
\hline Chacra Subercaseaux, tinto & R. Subercaseaux & 11.8 & 4.31 & $\begin{array}{l}\text { Correcto de gusto; el fruto persiste } \\
\text { bien en el paladar; sabor agradable. }\end{array}$ \\
\hline Viña Limache, tinto 1882 & Ex Urmeneta & 13.5 & 4.65 & $\begin{array}{l}\text { Añejo, fino, correcto de gusto; fruto } \\
\text { persiste bien en el paladar; sabor } \\
\text { agradable; bueno. }\end{array}$ \\
\hline Viña Panquehue, tinto 1885 & M. Errázuriz & 12.0 & 4.16 & $\begin{array}{l}\text { Añejo, fino, correcto de gusto; el } \\
\text { fruto persiste bien en el paladar; sa- } \\
\text { bor agradable; bueno. }\end{array}$ \\
\hline
\end{tabular}

75 Gustavo Verniory, Diez Años en la Araucanía 1889-1899, Santiago, Ediciones de la Universidad de Chile, 1975, 353. 


\begin{tabular}{|c|c|c|c|c|}
\hline Vino & $\begin{array}{l}\text { Propietario } \\
\text { de viña }\end{array}$ & $\begin{array}{l}\text { Alcohol } \\
\text { \% en } \\
\text { volumen }\end{array}$ & $\begin{array}{l}\text { Acidez } \\
\text { en } \mathrm{SO}_{3} \mathrm{HO} \\
\text { por litro }\end{array}$ & Comentario textual \\
\hline Finca Limache, tinto & Aracena Lira & 14.2 & 6.12 & $\begin{array}{l}\text { Vino añejo, de buen gusto, el frutc } \\
\text { persiste bien en el paladar. }\end{array}$ \\
\hline La Florida, tinto & Rojas Salamanca & 15.0 & 5.29 & $\begin{array}{l}\text { Añejo, fuerte en alcohol; franco de } \\
\text { gusto, sabor bastante agradable; lo } \\
\text { suponemos alcoholizado. }\end{array}$ \\
\hline Hacienda Limache, blanco & D. Gana & 12.0 & 5.24 & $\begin{array}{l}\text { Vino blanco añejo, correcto de gus } \\
\text { to, de sabor agradable y bueno. }\end{array}$ \\
\hline Santa Rita, blanco & \multicolumn{2}{|c|}{ Fernández Concha 13.2} & 4.80 & $\begin{array}{l}\text { Vino blanco delgado por naturale- } \\
\text { za; bastante fruta y correcto de } \\
\text { gusto. }\end{array}$ \\
\hline
\end{tabular}

Manuel Rojas, Tratado de Viticultura i Vinificación, segunda edición, Santiago, Imprenta y Encuadernación Barcelona, 1897, 585-586.

Los comentarios dejan la impresión de que se trataba de vinos buenos pero no excepcionales. Girard agregaba que algunas otras muestras, no incluidas en la tabla anterior, presentaban un principio de fermentación o un gusto a terroir (terruño) no agradable. Encontramos un testimonio similar a propósito de unas muestras de vinos chilenos enviadas a dos casas de comercio de champaña para consultarles acerca de la posibilidad de elaborar vinos espumosos a partir de ellos. Estas contestaron que los blancos conservaban "el gusto de terroir" que, sin ser desagradable, era "característico de todos los vinos exóticos en general". En cuanto a los tintos, una dijo que "tenía un bonito color y un gusto agradable [y que] mezclado con vinos más débiles y fríos se obtendría un buen resultado". La otra lo calificó de muy bueno y que "podría pasar por todas partes como vino de la Gironda". ${ }^{76}$ Salvo esta última, las opiniones en general coinciden en que los vinos chilenos no sabían igual que los franceses; de ahí que, sea por razones de calidad o por esnobismo los vinos importados tuvieron una cierta participación en el segmento superior del mercado.

\section{LAS IMPORTACIONES}

Aunque la importación de vino a Chile es tan antigua como el asentamiento español, la apertura del comercio exterior a raíz de la Independencia abrió la gama de posibilidades al paladar. Los vinos importados solo representaban una pequeña fracción del consumo nacional, alcanzando un máximo promedio de 6,4 por ciento a comienzos de los años 1870 , pero su significación social y cultural fue mucho mayor de lo que reflejan las cifras.

76 "La fabricación del champagne y del oporto en Chile", Boletín de la Sociedad Nacional de Viticultores, $\mathrm{N}^{\circ} 4$, noviembre 1897, 131-40 


\section{CUADRO $\mathrm{N}^{\circ} 5$}

IMPORTACIONES Y PRODUCCIÓN LOCAL DE VINOS 1846-1913

\begin{tabular}{lcc}
\hline Quinquenio & Total vinos, mostos y & Total de vino \\
y burdeos nacionales & importado &
\end{tabular}

Miles de litros promedio

\begin{tabular}{lccl}
\hline $1846-1850$ & 250 & & \\
$1851-1855$ & 616 & & \\
$1856-1860$ & 677 & 430 & 3,01 \\
$1861-1865$ & 13.872 & 640 & 3,79 \\
$1866-1870$ & 16.278 & 1.353 & 6,39 \\
$1871-1875$ & 19.799 & 904 & 4,33 \\
$1876-1880$ & 19.970 & 833 & 4,10 \\
$1881-1885$ & 19.464 & 711 & 4,47 \\
$1886-1890$ & 15.179 & 770 & 5,48 \\
$1891-1895$ & 13.293 & 358 & 3,37 \\
$1896-1900$ & 10.256 & 339 & 1,25 \\
$1901-1905$ & 26.825 & 700 & 4,51 \\
$1906-1910$ & 14.831 & 528 & 4,37 \\
$1911-1913$ & 11.545 & & \\
\hline
\end{tabular}

Fuentes: Anuario Estadístico de la República de Chile, Sinopsis Estadística, Estadística Comercial de la República de Chile. 1846-1913

A diferencia de lo que sucede con la producción local, las estadísticas de importación de vinos están publicadas de forma continuada desde $1844^{77}$. Una muestra de la situación en los años anteriores la encontramos en los datos recogidos por Claudio Gay sobre la importación de vinos por Valparaíso en 1834. Esta cifra, que representa la casi totalidad de lo internado al país, alcanzaba a unos 96 mil litros; un decenio más tarde, el total llegaba a 236 mil litros $^{78}$. El Gráfico $\mathrm{N}^{\circ} 4$ muestra el total de importaciones por quinquenios entre 1846 y 1913 , con la distinción entre tintos y blancos y entre vinos a granel y embotellados.

77 La Biblioteca Nacional conserva estadísticas anteriores desde 1840 pero, al parecer, están manuscritas. Las estadísticas para los años 1901 a 1905 no distinguen entre tintos y blancos, por lo que ha sido necesario establecer la proporción de uno y otro interpolando los datos de los años inmediatamente anterior y posterior.

78 Importaciones para el consumo nacional que ingresaron a Valparaíso desde el 1 de enero hasta el 31 de diciembre de 1834. AN Claudio Gay Vol. 45 (ex 54) fs 12-24. 


\section{GRÁFICO N4}

IMPORTACIÓN DE VINOS POR QUINQUENIO POR TIPOS Y ENVASES, 1846-1913

EN MILES DE LITROS PROMEDIO ANUAL ${ }^{79}$

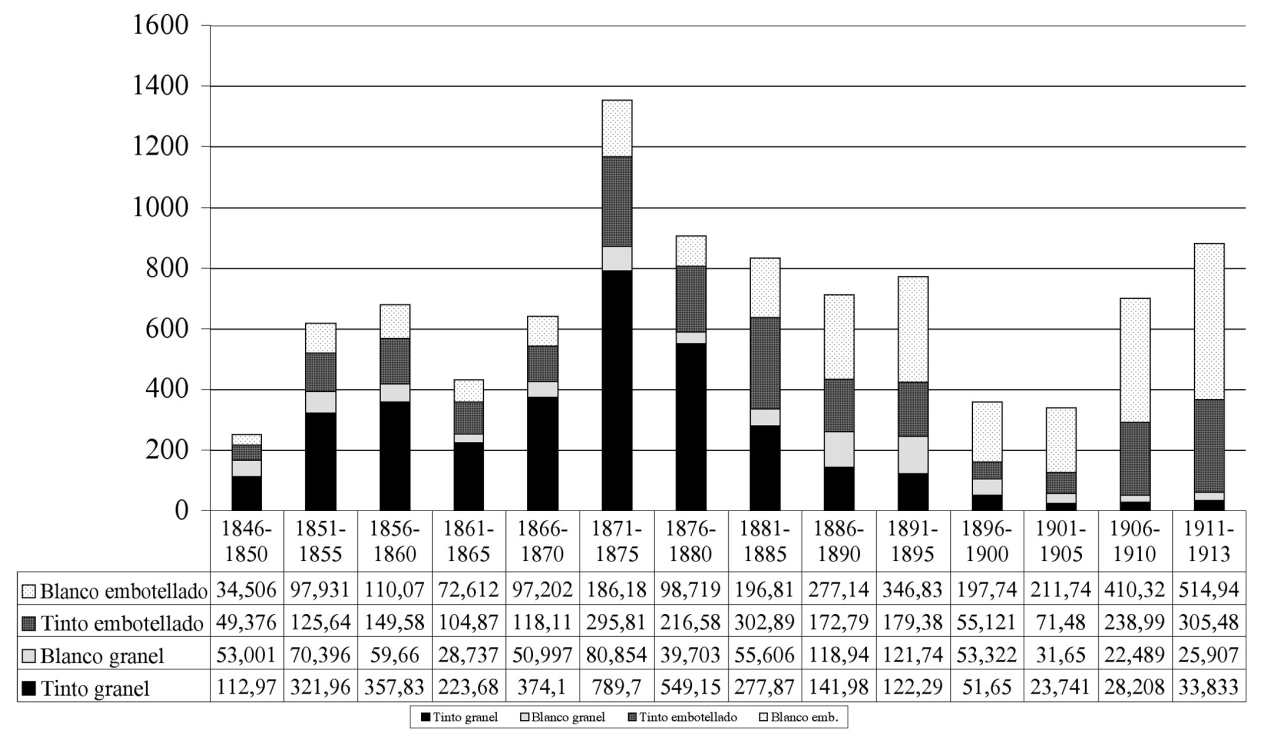

Fuente: Estadística Comercial de la República de Chile 1846-1913.

Las importaciones presentan un aumento sostenido hasta 1876. La caída en el volumen de las importaciones en los años siguientes coincide tanto con el deterioro de la economía chilena y la caída en el valor de nuestra moneda que encarecía el producto importado, como con el efecto de la filoxera que afectaba los viñedos europeos al mismo tiempo que mejoraba la calidad del producto local. Luego de la Guerra del Pacífico y la consiguiente riqueza, los volúmenes totales tienden a mantenerse y las menores importaciones de tintos a granel se compensan con el aumento de los vinos blancos embotellados. El aumento en el precio de los vinos importados, conforme a las estadísticas, sumado a los efectos de la crisis económica de la segunda mitad de la década de 1890, repercute sobre los volúmenes importados y la baja se prolonga durante los primeros años del nuevo siglo. Sin embargo, la bonanza económica posterior y la baja del precio se traducen en un mayor consumo de vinos importados, en especial el champaña ${ }^{80}$.

Las estadísticas del siglo XIX no distinguen entre los diversos tipos ni calidades, aunque se deja constancia de su existencia. Es así como la Estadística Comercial para

79 Se ha optado por cortar la serie en 1913 por los efectos que tuvo la Primera Guerra Mundial sobre las importaciones. El volumen de vinos embotellados se ha calculado a razón de 9 litros por docena. Las cifras para el trienio 1911-1913 corresponden al promedio de cada año.

80 El valor aduanero de los vinos embotellados aumentó de 10 a 20 pesos de $18 \mathrm{~d}$. por docena en 1898; baja a 12 pesos en 1903, para subir a 18 pesos en 1908 y a 30 pesos en 1912. 
1857 aclara que las cifras para vino blanco incluyen el champaña, el jerez, el vino moscatel, pajarete, Frontiñan, "vino Borgoña", "vino Sauterne", "vino Barsac" y otros, mientras que los tintos comprendían oporto, málaga, "Burdeos-Carlón", San Julián, Priorato, Medoc, San Vicente y demás ${ }^{81}$. Para 1866 se agregan a los blancos el vino del Rhin, el vermouth, los graves y también el de Málaga antes incluido entre los tintos $^{82}$. La presencia de estos tipos de vinos en el mercado nacional la confirma un anuncio de un remate de vinos en Valparaíso en 1836, donde se señala que el surtido incluye "Burdeos, Xerez, Oporto, Madera, Champaña, etc. en pipas y en botellas"83.

Quizás por la creciente gravitación que adquieren algunos de estos tipos dentro del conjunto, las estadísticas a partir de 1905 consideran en forma separada las importaciones de oporto, champaña, vermouth y jerez del resto de los vinos. Los cuadros siguientes demuestran claramente que, para entonces, estos últimos tipos representaban la mayor parte de las importaciones de blancos y que el oporto tenía una fuerte incidencia en las importaciones de tintos. Es preciso tener en cuenta lo anterior al considerar los países de origen de los vinos importados.

\section{GRÁFICO N ${ }^{\circ} 5$}

\section{VINOS BLANCOS EMBOTELLADOS POR TIPOS 1905-1913}

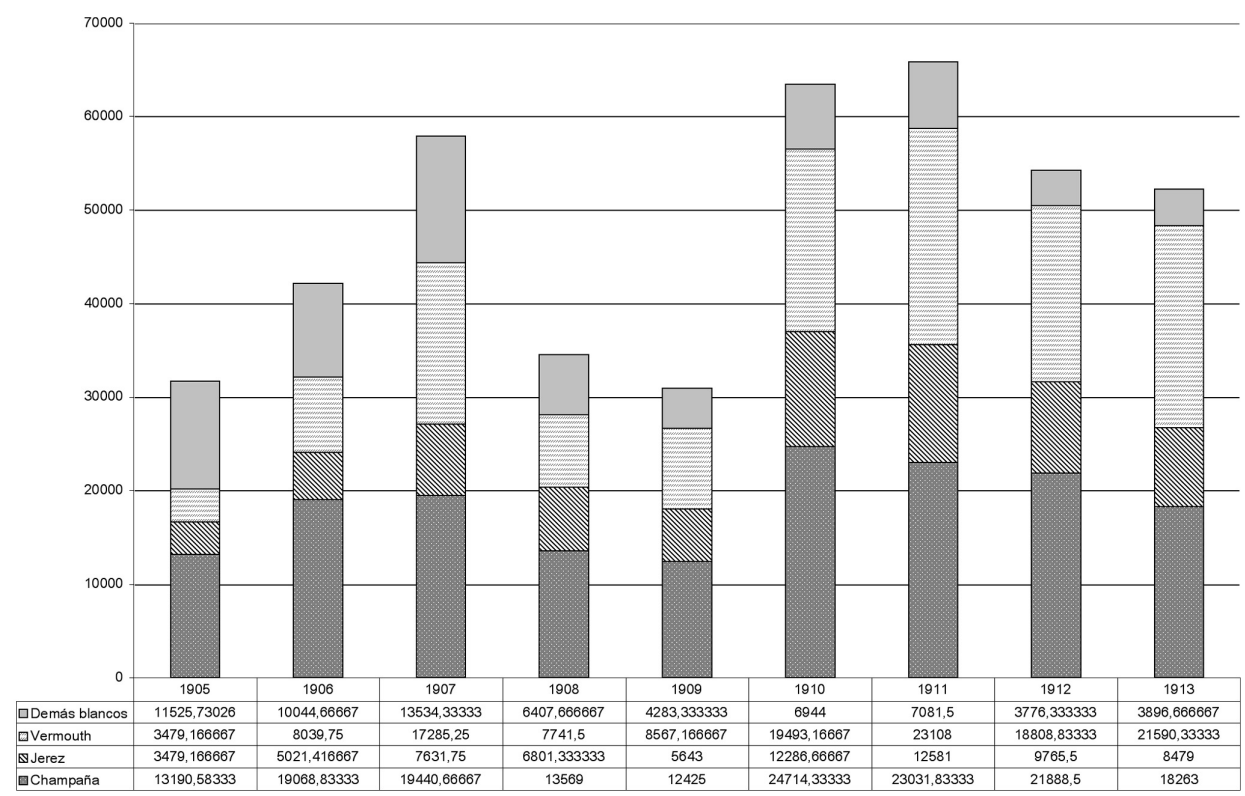

Fuente: Estadística Comercial de la República de Chile, 1905-1913.

81 Estadística Comercial de la República de Chile correspondiente al segundo semestre del año 1857, Valparaíso, Imprenta del Diario, 1858, 108.

82 Estadística Comercial de la República de Chile correspondiente al año de 1866, Valparaíso, Imprenta y Librería del Mercurio, 1867, 229-233.

83 El Mercurio, Valparaíso, 12-10-1836, 3. 


\section{GRÁFICO Nº}

VINOS TINTOS EMBOTELLADOS POR TIPOS 1905-1913

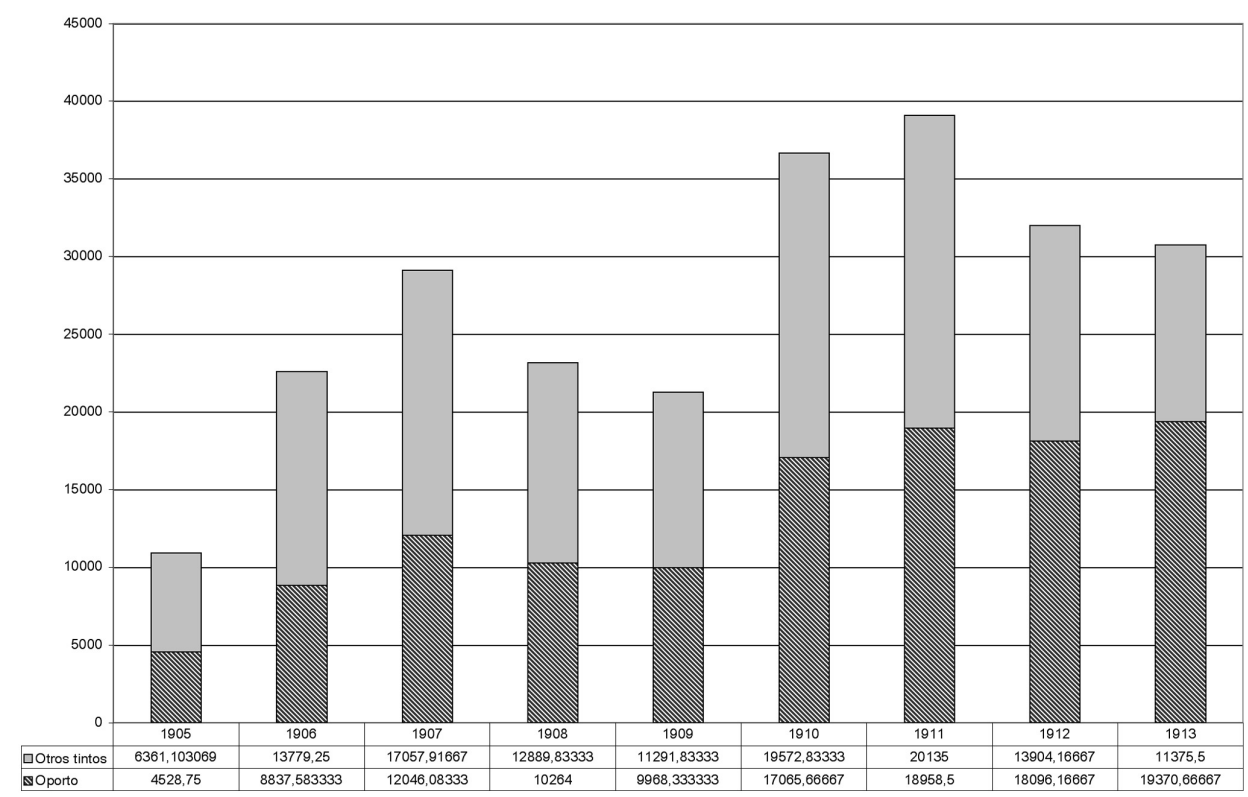

Fuente: Estadística Comercial de la República de Chile, 1905-1913.

La casi totalidad de los vinos extranjeros proviene de cuatro o cinco países: Francia, España, Italia, Alemania y, en el caso de los tintos, Portugal. Sin embargo, en las estadísticas Gran Bretaña tiene un lugar importante por las reexportaciones desde dicho país, una función que también cumple Alemania y que abulta las cantidades registradas con ese origen.

En términos generales, España había perdido su antiguo predominio a favor de Francia, el proveedor más importante durante todo el siglo XIX. No obstante, hay variaciones en la incidencia de los distintos países conforme se trate de vinos tintos o blancos, a granel o embotellados. En el caso de los vinos tintos, Francia mantuvo una supremacía incontrastable hasta los años 1880, según se aprecia en los Gráficos 7 y 8. A partir de entonces hay una creciente competencia de parte de Gran Bretaña, España y Portugal, la que se explica mayormente por la incidencia del oporto y similares.

La tendencia general arriba mencionada es particularmente aplicable a los vinos a granel de Francia. Mientras se renovaba la viticultura chilena se importaron cantidades crecientes de vino suelto, lo que dejó de justificarse en la medida que mejoraba el vino nacional, a la vez que se depreciaba la moneda chilena y empeoraba el vino "francés". En efecto, a raíz de la epidemia de filoxera, ese país entró a importar cantidades apreciables de vino barato para compensar la caída de la producción interna. A comienzos del siglo XX los precios de los vinos ordinarios en 
Francia habían descendido en forma significativa, dando origen a las protestas de los viñateros locales ${ }^{84}$. No tenía sentido traer estos vinos ordinarios en barriles, pero sí lo tenía importar vinos embotellados con etiquetas de renombre, sea en forma directa o a través de terceros países como Gran Bretaña y Alemania, que podían venderse a buen precio. En el caso de los vinos oporto que, según vimos, adquieren creciente demanda con el tiempo y que no tienen una concurrencia local, hay también una tendencia a la venta en botellas, que son más prácticas para el consumidor que los barriles. De ahí que las importaciones de tintos embotellados no experimenten una caída tan sensible hasta mediados de los 90 y que tenga un repunte tan marcado después.

\section{GRÁFICO N 7}

IMPORTACIONES DE VINOS TINTOS A GRANEL POR PAÍSES Y QUINQUENIOS 1846-1913. MILES DE LITROS PROMEDIO ANUAL

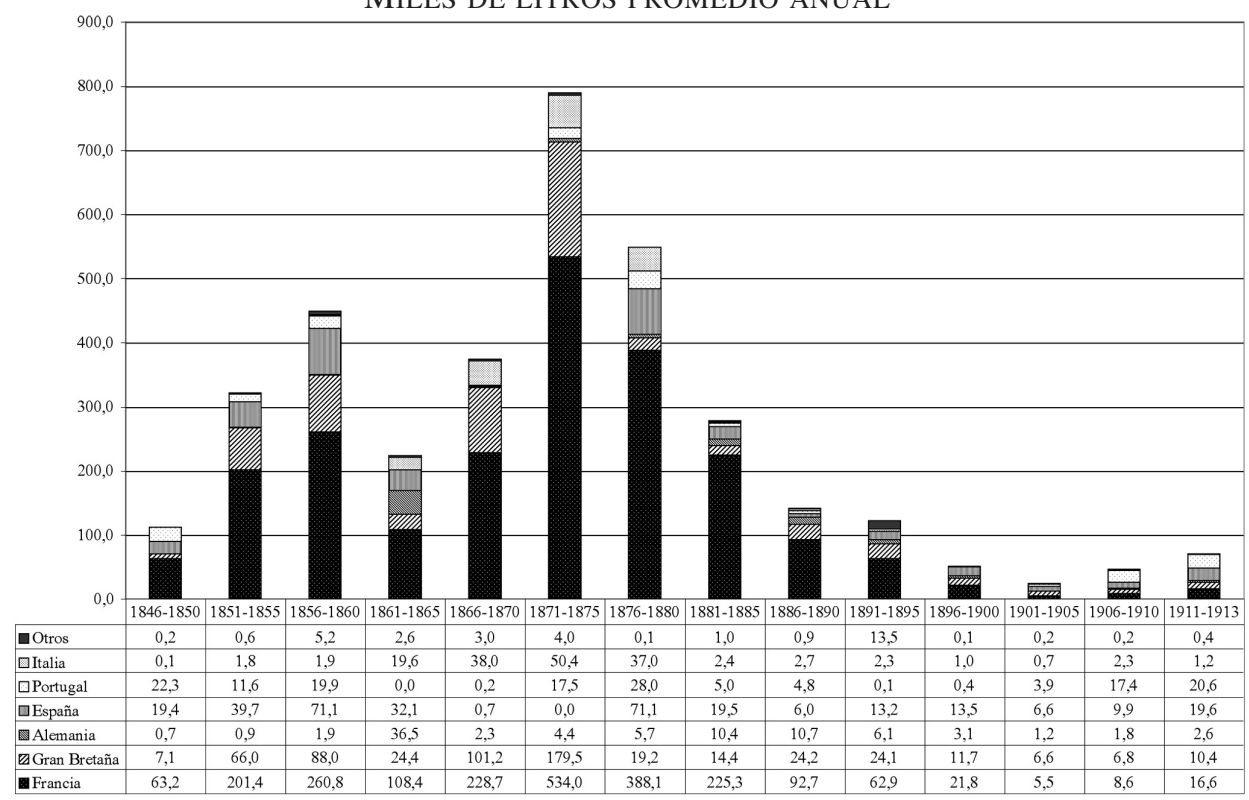

Fuente: Estadística Comercial de la República de Chile 1846-1913.

84 Acerca de los efectos de la filoxera sobre el mercado de vinos francés véase James Simpson, Phylloxera, Price Volatility and Institucional Innovation in France's Domestic Wine Market, 18701911, Universidad Carlos III de Madrid, Economic History and Institutions Dep. Working Paper 0446, 34 p. www.uc3m.es/depto/HISEC/doctrab/2004/wp04-46(02)pdf. Nov. 2004 
En cuanto a los vinos blancos a granel los volúmenes máximos se alcanzan en la segunda mitad de los 80 y primera mitad de los 90. La fuerte presencia de Gran Bretaña y España demuestra que las importaciones de jerez y vinos similares, como el de Málaga o el Madeira, son, en general, tanto o más significativas que las de los vinos franceses y alemanes. Influye, por cierto, que el jerez no tuviera mayor competencia local, aunque sí se fabricaban en Chile otros vinos dulces.

El Gráfico No 9 muestra que España era el segundo mayor proveedor de vinos blancos a granel después de Gran Bretaña y muy por encima de Francia, por lo menos hasta 1865. En el decenio siguiente hasta 1875, y como corolario de la guerra con la antigua metrópoli, Gran Bretaña reemplazó a España como lugar de procedencia. En los años 80 y hasta mediados de la década siguiente las importaciones desde Francia crecieron en forma significativa al mismo tiempo que se mantenían los niveles de importación desde Gran Bretaña y de España. Sin embargo, desde mediados de los años 90 los volúmenes importados descendieron en forma muy marcada, con una fuerte presencia de los vinos españoles, lo que hace pensar en la gravitación del jerez dentro del total.

\section{GRÁFICO Nº 8}

IMPORTACIONES DE VINOS TINTOS EMBOTELLADOS POR PAÍSES Y QUINQUENIOS 1846-1913

MiLES DE DOCENAS PROMEDIO ANUAL

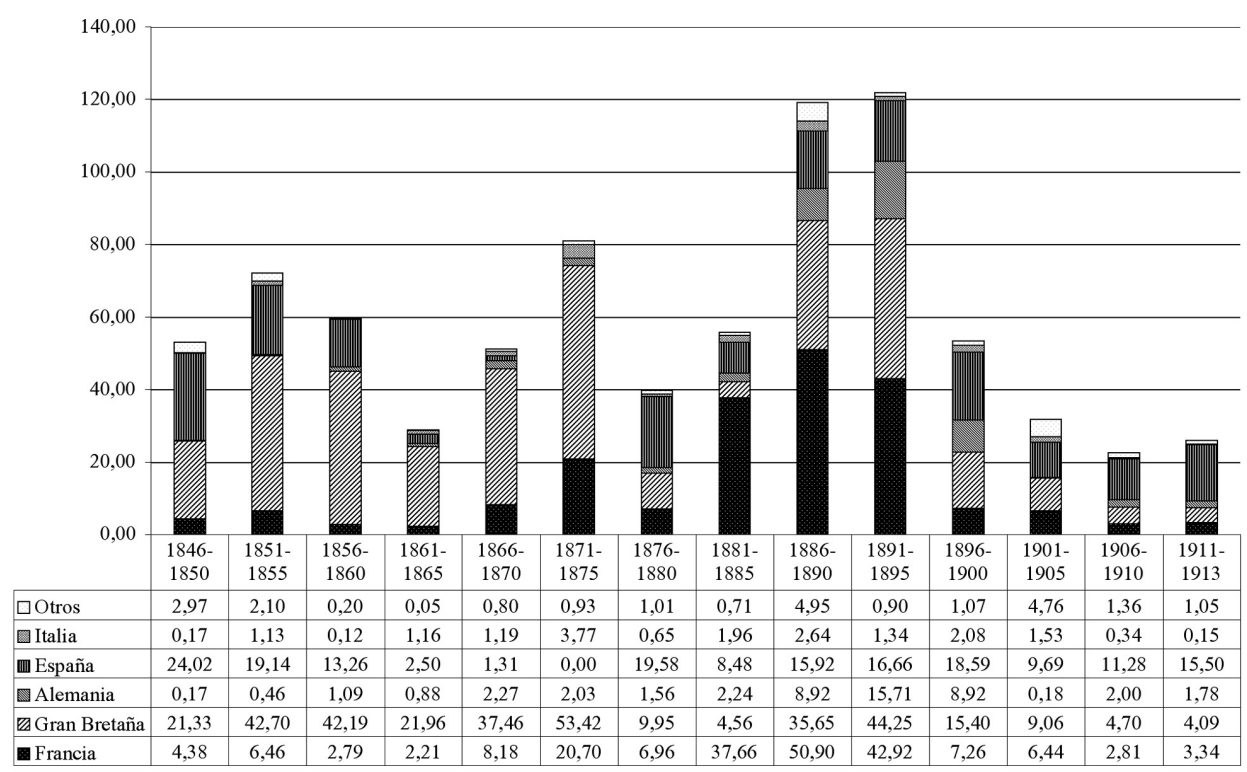

Fuente: Estadística Comercial de la República de Chile 1846-1913. 


\section{GRÁFICO Nº}

IMPORTACIONES DE VINOS BLANCOS A GRANEL POR PAÍSES Y QUINQUENIOS, 1846-1913.

MiLES DE LITROS PROMEDIO ANUAL

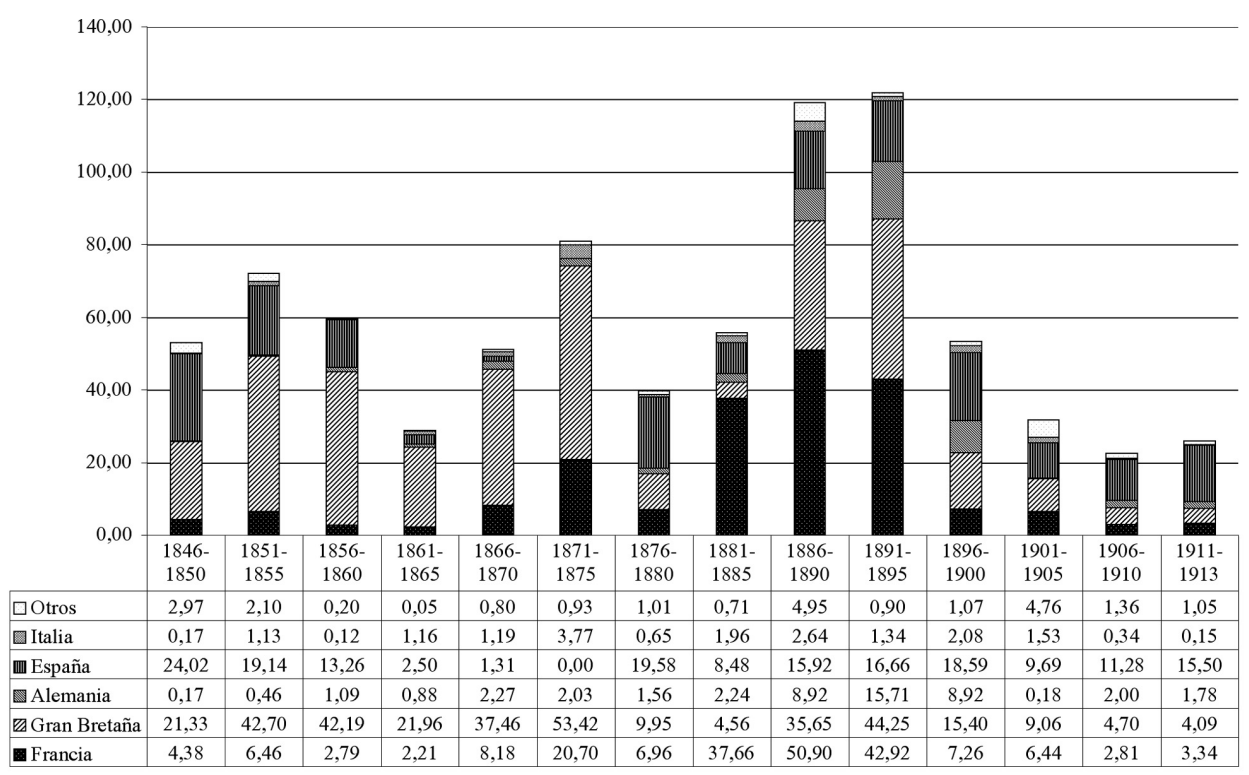

Fuente: Estadística Comercial de la República de Chile 1846-1913.

Tal como se observó más arriba, la importación de vinos blancos embotellados presenta una evolución distinta al resto, más sensible a los ciclos de la economía que al desarrollo de la producción local. Hay un aumento creciente desde mediados de los años 1860, interrumpido solo durante la segunda mitad de los 70 y a finales del siglo, períodos ambos de recesión económica. El estancamiento se prolongó durante los primeros años del siglo XX, pero pronto se produjo el repunte y se superaron los niveles anteriores. La primera y principal explicación es la incidencia del champaña y el jerez, vinos que no eran elaborados en Chile; la segunda, según ya vimos, es la calidad de los blancos locales que no alcanzaba el nivel de los tintos (Ver Gráfico No 10 ). 


\section{GRÁFICO N 10}

IMPORTACIONES DE VINOS BLANCOS EMBOTELLADOS POR PAÍSES Y QUINQUENIOS, 1846-1913.

MILES DE LITROS PROMEDIO ANUAL

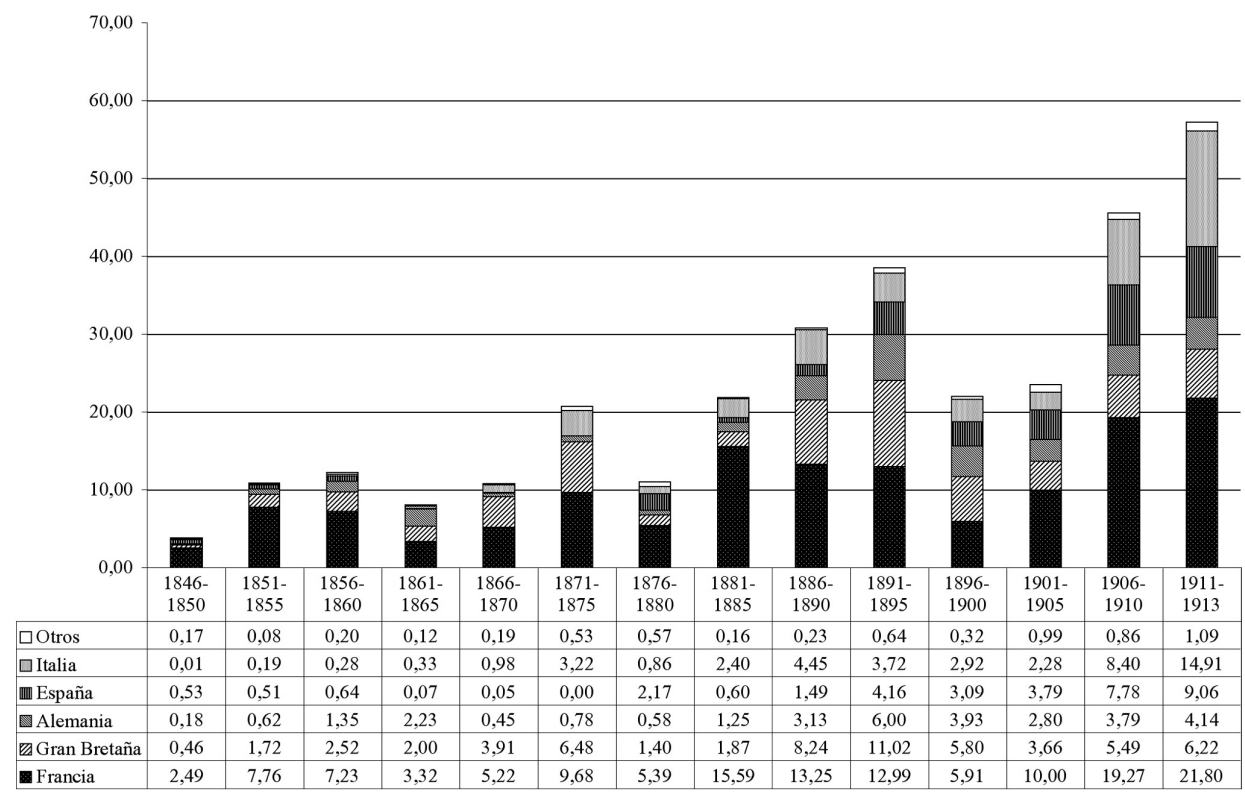

Fuente: Estadística Comercial de la República de Chile 1846-1913.

Las importaciones desde Francia, que corresponderían mayormente a champaña, guardan una consonancia más estrecha con los mencionados ciclos económicos. Las importaciones desde Gran Bretaña y España estaban constituidas principalmente por jerez y otros vinos dulces, aunque también hay que considerar las reexportaciones de vinos franceses y otros desde el Reino Unido. La mayor incidencia de Alemania deriva de la demanda por los vinos del Rin. En cuanto a Italia, buena parte de ellas corresponde al vermouth, ingrediente de los cócteles; esta novedad se había introducido en la década de 1880 y para fines de siglo había cobrado creciente aceptación en la juventud elegante ${ }^{85}$. Confirma esta tendencia la incorporación de "cocktaileras" de metal como un ítem específico en la tarifa de avalúos de $1896^{86}$.

85 Luis Orrego Luco, Memorias del Tiempo Viejo, Santiago, Ediciones de la Universidad de Chile, 1984. 53-54 y 558; Julio Subercaseaux, Reminiscencias, Santiago, Editorial Nascimento, 1976, 209 y 239.

86 Tarifa de Avalúos, 1896, p. 5 Las cocteleras de "metal ordinario niqueladas o no" se tasaban a \$ 6.60 el kilo neto y las de metal plateado a \$16; ambas pagaban 35\% de derechos, la tasa más alta. 


\section{CHAMPAÑA, JEREZ Y OPORTO}

Visto el volumen que alcanzan las importaciones de estos tipos de vinos es preciso hacer algún comentario al respecto. Al parecer, la presencia del champaña en Chile se remonta a la Independencia. La primera referencia a su consumo la encontramos en la cuenta de gastos del banquete dado por Bernardo O'Higgins en honor de Lord Cochrane el 6 de diciembre de 1818, que cobraba "24 botellas de Champay a 22 pesos la docena" ${ }^{87}$. También aparece mencionado a raíz del sarao ofrecido en enero de 1840 a los vencedores de Yungay, y ocupa un lugar destacado en el famoso baile efectuado el 26 de septiembre de 1841 con motivo de la ascensión de Manuel Bulnes a la Presidencia. Durante la correspondiente cena se consumieron 384 botellas de champaña, bastante más que las 120 de oporto, 96 de Frontiñán, 96 de Rin, 48 de jerez, 72 de málaga y 72 de burdeos ${ }^{88}$.

La industria del champaña estaba por entonces en su infancia. Fue en 1815 cuando se establecieron dos de las firmas más reputadas: las casas de Moet et Chandon "la más rica de la Champaña", en Epernay, y la de Veuve Cliquot en Rheims. Otra productora importante, la casa Roederer, fue fundada en Rheims por el alemán Luis Roederer en 1837 para hacer competencia a los señores Werle propietarios de la casa Veuve Cliquot y sucesores de la viuda ${ }^{89}$. Con el tiempo, las firmas más grandes y famosas pasaron a ser conocidas como las Grandes Marques o "grandes marcas". En 1882 tres de las principales casas de Champagne formaron el Syndicat des Grandes Marques. En menos de un año se incorporaron otras 19 firmas y como resultado pasó a representar casi todo el comercio de la champaña en aquel entonces ${ }^{90}$.

Sin embargo, para los años 40, las grandes casas productoras aún no estaban acreditadas en Chile. En un anuncio en El Mercurio de Valparaíso de 1841, Santos Tornero ofrecía "Champaña superior en botellas y medias botellas" pero sin especificar marcas ${ }^{91}$. Otro aviso de la Tienda Francesa de 1845 ofrecía champaña en los mismos tipos de envase sin tampoco indicar la marca. Por entonces, Ravenscroft hermanos ofrecía un champaña "Messiac y Loisson", nombre que no pasó a integrar el mencionado Syndicat y que probablemente corresponda al de los embotelladores ${ }^{92}$.

En cambio, ya en los años 1870 , el comercio de Valparaíso y Santiago tenía a la venta varios de los champañas más reputados. El más conocido parece haber sido el de Roederer importado por Weir Scott y Brace Laidlaw de Valparaíso,

87 B. Vicuña Mackenna, El Ostracismo del Jeneral Don Bernardo O'Higgins, Valparaíso, Imp. y librería del Mercurio, 1860, 550-552. El champaña no aparece mencionado ni en la celebración del 18 de septiembre de 1812 en la Casa de la Moneda ni en el banquete ofrecido a O'Higgins por Felipe S. del Solar en febrero de 1817 (Manuel Antonio Talavera, Revoluciones de Chile, CHICh tomo XXIX, Santiago, 1937, 649-650; Vicente Pérez Rosales, Recuerdos del Pasado (1814-1860), Biblioteca de Escritores de Chile III, Santiago, Imprenta Barcelona, 1910, 43.

88 El Araucano (Santiago) $\mathrm{N}^{\circ}$ 580, 1-10-1841, 3-4.

89 Julio Menadier "Porvenir de la vinicultura nacional", Boletín de la Sociedad Nacional de Agricultura, Vol. XI, Nº 9, febrero de 1880, 161-164; Vol. XI No 10, marzo 1880, 190-193.

90 http://www.intowine.com/champagne3.html 26-9-2002.

91 El Mercurio, Valparaíso, 12-3-1841, p. 1.

92 Ibid., 4-9-1845, p. 3; Id.9-9-1845, p. 3. 
que tenía como agente en Santiago a Diego Mitchell, y en los años siguientes por Ernest Fontaine y Besa y Cía. en Valparaíso ${ }^{93}$. Weir Scott importaba también el champaña Veuve Clicquot, que en los 80 se encontraba también en los negocios de Roberto Eyzaguirre y de Ricardo Vigil Zañartu. Brace Laidlaw y Mitchell también ofrecían un Heidsieck Carte Blanche, y el Moet et Chandon "Extra"94, mientras que el Ayala, Chateau D'Ay, aparece ofrecido Jorge Brownell \& Ca. de Valparaíso en $1876^{95}$. No eran estas las únicas "grandes marcas" disponibles, a juzgar por los menús de la época donde aparecen, junto a las mencionadas, G. H. Mumm y otras ${ }^{96}$.

Además de las "grandes marcas", se vendían champañas con el nombre de las casas exportadoras de Rheims, Epernay y Ay, fabricados con uva de las comarcas vecinas. Es el caso del champaña de Fenwick, Constans \& Cie., que ofrecían los ya mencionados Brace, Laidlaw y Mitchell; el Fisse, Trillon y el Foucher Bruch \& Cie., ambos de Oderica y Ca. de Valparaíso, y el de F. Mercier \& Co de Spencer y Cía. ${ }^{97}$. Otro champaña con creciente presencia en el mercado, conforme a los menús de la época, es el Saint Marceaux; en las década de los 70 y 80 lo vendía Besa y Salinas y Roberto Eyzaguirre, y en años posteriores, Aguiar Braga y Cía., y sus sucesores, los señores E. Domínguez, que declaraban ser los únicos importadores $^{98}$. También aparece anunciado en venta un "Sillery Moseaux" [Mousseux], vino espumante de la región de Champaña, que sin serlo se vendía con el nombre de champaña, y un champaña "especial para ponche", presumiblemente más barato, que vendía Ricardo Vigil en $1884^{99}$. Ya a comienzos del siglo XX aparecen otros vinos espumantes que se sirven como champaña, como es el de Cinzano, anunciado en 1913, o un Grand Royale Champagne (1916), en cuya etiqueta se lee "Faure-La Cisterna", y que era distribuido por L. y A. Dussaillant, los propietarios de la viña Casa Blanca ${ }^{100}$. Otro testimonio de la oferta de vinos espumantes sucedáneos del champaña es un menú del Paris Hotel para sus "viernes de moda" en 1910. En un costado del mismo se ofrecía el "champagne Paris Hotel" a ocho pesos la botella, mientras que en el otro se anunciaba la "Specialité 'Big Tree' sparkling muscatel"

93 Guía-Almanaque de Valparaíso para 1875. Valparaíso, Imprenta del Mercurio de Tornero y Letelier, 1874. 16, Jacinto Núñez, Almanaque divertido para 1875. Santiago, Imprenta de la República, 1874, s.p; Almanaque Comercial para el año bisiesto de 1892, Valparaíso, s.p.d.i., 1892, 110; Almanaque pintoresco para 1900, Valparaíso, Librería del Mercurio, 1900, 54.

94 Almanaque de la New York..., Santiago, Imprenta Cervantes, 1884, 32.

95 El Mercurio, Valparaíso, 4-5-1876, 1.

96 Véase, por ejemplo, El Diario Ilustrado, 22-6-1906; El Ferrocarril, 9-5-1900 y 20-11-1900 y Eduardo Balmaceda Valdés, Un mundo que se fue, ob. cit. 167.

97 Almanaque divertido para 1873. Publicado por Jacinto Núñez, Santiago, Imprenta de la República, 1872, s.p.; Almanaque Comercial para 1884, Valparaíso, Imprenta de La Patria, 1883, 41; André L. Simon, The History of Champagne, London, Octopus Books Limited, 1971, 180-182. Se ha corregido la ortografía de los nombres.

98 Román Vial, Almanaque nacional para 1877, Valparaíso, Imprenta del Mercurio, 1876, 61; Almanaque para 1887 de La Libertad Electoral, Santiago, Imprenta de la Libertad Electoral, 1887, 19 y 61; Zig-Zag, Año XII, N 593, 1-7-1916.

99 Almanaque de la New York..., Santiago, Imprenta Cervantes, 1884, 32. Sobre Sillery: http:// www.jaxhogan.co.uk/genealogy/sillery/Sillery_champagne.htm, 26-7-2003

100 Zig-Zag, Año IX, N 462, 27-12-1913; íd. Año XII, N 602, 2-9-1916. 
al mismo precio, con la diferencia que se disponía de la bebida en "magnums" a 16 pesos y de medias botellas a 4 pesos ${ }^{101}$.

Es difícil cuantificar la situación descrita y las estadísticas no ayudan demasiado. En el Gráfico $\mathrm{N}^{\circ} 11$, que muestra la proporción de vinos espumantes según país de importación, entre 1905 y 1913, Francia aparece con el 70 por ciento del mercado, pero hay que tener presente que no todo el vino espumante francés es propiamente champaña. Por otro lado, una parte del vino espumante proveniente de Gran Bretaña puede corresponder efectivamente a champaña. El tema queda abierto.

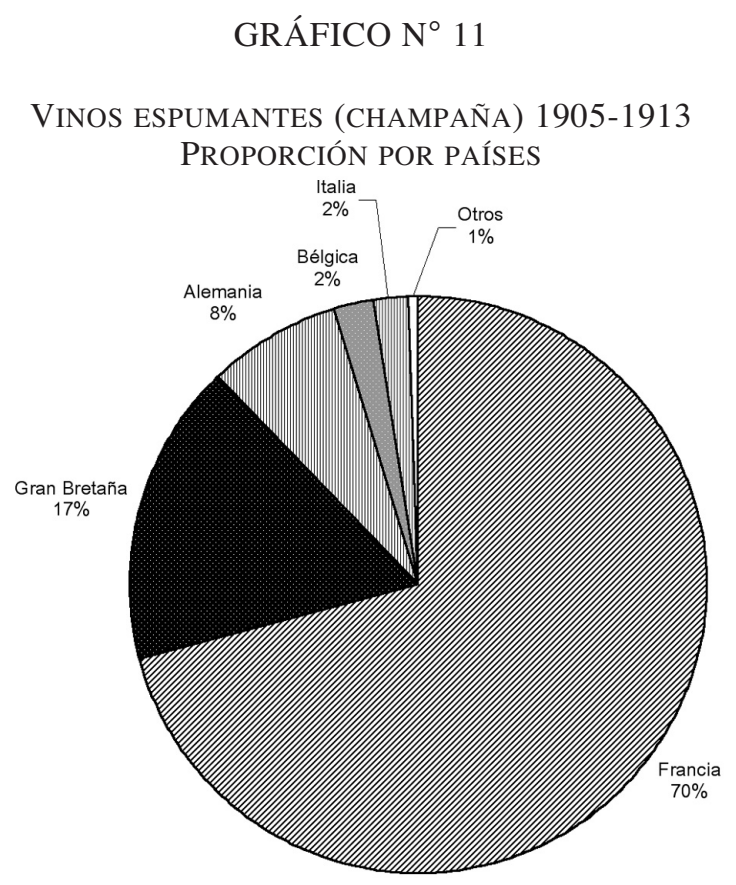

Fuente: Estadística Comercial de la República de Chile, 1905-1913

Con todo, tanto las estadísticas como los testimonios cualitativos apuntan a la difusión de su consumo. Ya para los años de la Guerra del Pacífico el champaña se había hecho común. Escribiendo en 1880, Julio Menadier señala que las victorias de esos años eran celebradas con champaña ${ }^{102}$. La prosperidad de los años siguientes debe haber aumentado el consumo. Luis Orrego Luco recuerda que en las fiestas y

101 Paris Hotel, Diner Concert. Orquesta Guerin. Viernes de moda, Menu. 19-8-1910. Original en el Museo Histórico Nacional.

102 Menadier "Porvenir" [83], 190-193

103 Orrego Luco [80], 58-59 y 155. 
los bailes de los años 80 , "el champaña corría a torrentes, sin mirar el gasto" 103 .

El influjo francés en los gustos chilenos no podía menos que aumentar la afición al champaña. Julio Subercaseaux cuenta que en una visita a la Exposición Internacional de Paris de 1889 descubrió el stand del Champagne,

reservado cada día para una marca diferente que servía al público a razón de tres francos el vaso. Estaba el champagne en todos sus tipos. El francés dulce, el americano medio seco, el inglés seco, acompañados de exquisitas galletas. Como pudimos apreciar y paladear, había no menos de veinticinco variedades de marcas, las que más nos gustaron fueron el "Deutz \& Geldermann", y el "Pommery \& Greno".

Con su amigo Julio Bittencourt, visitaba el local todos los días, paladeando tres tipos en cada visita ${ }^{104}$. El champaña era la bebida de rigor en los banquetes a la hora de los postres y de los brindis, pero también podía reemplazar al vino a lo largo de la comida, como solían hacerlo algunos gourmets como el propio Julio Subercaseaux y Agustín Edwards Mac-Clure ${ }^{105}$.

La elaboración de esta bebida tan apreciada implica, como es sabido, un proceso complejo. Este vino espumante oriundo de la región de Champagne, se fabrica a partir de uvas pinot negras (o más exactamente de color azul oscuro) y blancas. El vino es objeto de una doble fermentación; la primera, natural, que tiene lugar en las bateas y barricas, y una segunda, producida dentro de la botella por la adición de vino azucarado, que genera las burbujas características de la bebida. Luego viene la remoción del sedimento formado al interior de la botella mediante los procesos de remuage (sacudimiento) y dégorgement (descorchado). Antes de salir de las bodegas se agrega a las botellas, un liqueur d'éxpedition, un pegajoso jarabe de azúcar con vino y una muy pequeña cantidad de aguardiente fino para impedir que continúe la fermentación. Otra diferencia con los vinos tradicionales franceses es que el champaña no proviene de una sola viña, sino que es resultado de una mezcla cuya composición es un secreto del fabricante, celosamente guardado ${ }^{106}$. La sofisticación del proceso descrito, además de los sabores particulares de los insumos, dificultaba la fabricación de champaña en Chile.

Lo anterior no fue obstáculo para que se intentara producir aquí esta bebida. Ya en la exposición agrícola de 1869, Luis Leclerc, de Curicó, exhibía su "champaña del país"107. Hubo un nuevo intento en los años 1890 según mencionamos a propósito de las muestras de vino enviadas a Francia para este efecto. Al concluir su informe sobre la materia, Alfonso Premis, jefe de la bodega de la Quinta Normal, declaraba que se podría producir "un buen vino espumoso" a partir de uva negra, separando de inmediato el orujo una vez de prensada -que es la forma como se

104 Subercaseaux, [80], 267.

105 Verniory [70,] 275.

106 Simon [91], 28-35.

107 Catálogo oficial de la exposición de Agricultura inaugurada solemnemente en Santiago el 5 de mayo de 1869, Valparaíso, Imprenta del Mercurio, 1869, 168. 
hace el champaña en Francia-, pero que "conservaría su bouquet particular a terroir y no tendría la limpidez que caracteriza a los buenos champañas"108. Según Luis Correa Vergara, su producción sistemática fue iniciada recién en 1914 por Alberto Valdivieso en la viña Santa Elena ${ }^{109}$.

El jerez, vino de aperitivo, se consumía regularmente en los banquetes para acompañar a los hors d'oeuvres. Como hemos visto, se importaba tanto en botellas como en barriles. Se traía desde España y también desde Gran Bretaña, cuyos nacionales tenían bastante injerencia en el comercio de este vino que encontraba gran aceptación en dicho país. Así la firma Brace, Laidlaw y Cía. de Valparaíso informaba en 1875 que las distintas clases de jerez que tenía a la venta eran traídos desde España por Edmundo Brace y Cía., “y embotellados por su casa en Glasgow, sin intervención de terceros", lo que permitía garantizar la calidad de los vinos y "ofrecerlos a precios sumamente moderados". Las distintas calidades de "sherry" ofrecidas llevan nombres ingleses: Union Club, London Club e Imperial Crown ${ }^{110}$.

Un buen surtido de jereces ofrecía el Emporio Inglés de Simpson y Ca. de Santiago. Los tipos anunciados, para su venta en barriles de 16 y 32 litros, eran el ámbar, continental, oro, seco, fino, añejo, amontillado oloroso, amontillado añejo, "Ladies", "Adela", y Pedro Ximénez corriente y superior, además de vino malvasía, madeira y málaga dulce blanco y negro que se incluían en este rubro ${ }^{111}$.

Algo semejante sucede con el oporto. Aunque originario de Portugal, buena parte de las importaciones venían a través de Gran Bretaña. También aquí nombres para las distintas calidades ofrecidas son significativos. Así, en 1876 Weir Scott \& Ca. anunciaba la venta de su Fine Port, Fine Old Port y London Club Port, mientras que dos décadas más tarde el Emporio Inglés de Simpson y Cía. de Santiago ofrecía no menos de 16 tipos de oporto, algunos con nombres de reminiscencia británica como el Golden, el Club de Londres, el Monopole, el Victoria y el Invincible, junto a otros como el Dorado, el Douro, el Corona Dorada y el Ne Plus Ultra, que, suponemos, era el de mayor jerarquía ${ }^{112}$. Tal como se refleja en las estadísticas, el oporto también se traía de España, como el de Carrey Hermanos de Tarragona ofrecido por H. Maupas de Valparaíso en 1875. Incluso se ofrecía, sin indicar origen, un "oporto extra-fino" blanco y de "gusto muy agradable"113. El oporto, al igual que el jerez, se vendía tanto en botellas como en barriles pequeños de 32 y 16 litros, y parecería que una parte pequeña pero creciente de la reducida importación de tintos a granel a fines del siglo XIX y comienzos del siglo XX correspondía precisamente a este tipo de vino (ver Gráfico $N^{\circ} 6$. En efecto, mientras las importaciones de tinto en barriles desde Portugal y Gran Bretaña entre

108 "La fabricación ..." [71], 131-140.

109 Correa Vergara, [32], II, 283. Véase también Del Pozo [1], 104

110 Guía-Almanaque de Valparaíso para 1875 [88], 16; Julio Chaigneau, Guía comercial de Valparaíso, 1874-75, Valparaíso, Imprenta de La Patria, 1874., s.p.

111 Itinerario de Trenes y Catálogo para 1896 de Simpson y Ca. Santiago, Imprenta Gutenberg, 1896, 17-18.

112 El Mercurio, Valparaíso, 4-5-1876, 1; Itinerario de Trenes [104], 17-18.

113 Almanaque Franklin para 1875, Valparaíso, Imprenta Colón, 1875, 23; El almanaque guía de la imprenta Victoria para el año de 1885, Santiago, Imprenta Victoria, 1884, 104. 
1861 y 1880 representaban poco menos del 30 por ciento de lo que se traía de Francia, entre 1885 y 1910 esta proporción había aumentado al 42 por ciento. A lo anterior contribuye que el oporto, a diferencia de los vinos tintos de Francia, no tenía una competencia nacional de calidad similar ${ }^{114}$.

\section{VINOS Y BANQUETES}

Las tendencias observadas respecto a los volúmenes de las importaciones a través del tiempo parecen confirmarse al revisar los vinos ofrecidos en los banquetes conforme aparecen en los menús de la época. Para este efecto hemos tomado una muestra de 55 menús fechados entre 1882 y 1927 que indican los vinos servidos en cada ocasión, distinguiendo entre los europeos y los provenientes de viñas nacionales con una tercera categoría para las ocasiones en que se sirven tanto vinos europeos como chilenos, o los menús que emplean denominaciones genéricas, como ser "sauternes", "rhin" o "bordeaux" u otras que no aclaran origen. La identificación de la viña productora chilena en el menú se puede entender como un testimonio del prestigio alcanzado por la misma. Más complejo es el caso de los nombres genéricos; es muy posible que se trate de los equivalentes nacionales, tanto por no indicar el chateau o la comarca respectiva, como por la frecuencia de imitaciones, según se explica más adelante. Es preciso tener en cuenta este factor que modifica sensiblemente la interpretación del Gráfico $\mathrm{N}^{0} 11^{115}$.

Más allá de si los vinos franceses eran de la proveniencia indicada, interesa saber cuáles eran los tipos más prestigiados. El canon para estos efectos es la clasificación efectuada con motivo de la gran Exposición Internacional de París en 1855. En esa oportunidad los tintos más selectos fueron clasificados en cinco categorías, los llamados Grands Crus, entendiendo por cru, el terroir o la comarca donde creció la vid. La medida de calidad fue elaborada por una conferencia de corredores de vino y se basó en el sobreprecio alcanzado por cada vino respecto de los años anteriores, remontándose hasta el siglo XVIII. Para 1910 existía una clasificación similar para los blancos del distrito de Sauternes, en la Gironda116.

114 Ver "La fabricación..." [71], 131-140, donde se informa de la misión encomendada a Alfonso Premis para estudiar la posibilidad de elaborar este producto.

115 Los menús provienen de las colecciones en poder de la sucesión de Carlos Peña Otaegui, del Museo Histórico Nacional, de Felipe Vicencio y de María Angélica Manrique, además de las extractadas de periódicos de época por Carlos Fariña en su trabajo de seminario. La distribución de menús por período es la siguiente: 1882-1892, 11 casos; 1895-1900, 8 casos; 1901-1905, 17 casos; 1906-1910, 11 casos; 1915-1927, 6 casos.

116 "Wine" en Encyclopaedia Britannica, $11^{\text {th }}$ Edition, XVIII, 721-723; la lista actual en http:// www.terroir-france.com/vin/grandscrusbordeaux.html 19-4-2003. 


\section{GRÁFICO N 12}

\section{VINOS NACIONALES E IMPORTADOS EN BANQUETES 1882-1927 PORCENTAJES POR PERÍODO}

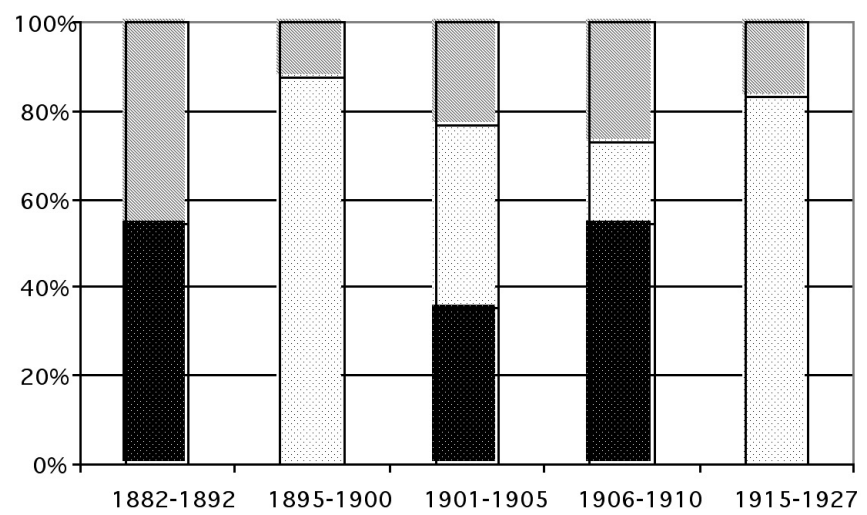

De los vinos mencionados en los menús y los ofrecidos en los negocios aparecen con mayor frecuencia el Château Lafite y el Château Margaux, entre los grands crus de primera clase. De la categoría siguiente figuran el Mouton Rothschild, el Pichon-Longueville y el Chateau Larose, como también un Pontet-Canet cuyo "chateau" aparece en la quinta categoría. De los blancos, el que más figura es el Chateau Yquem -“el vino de las ostras", como lo denomina Benjamín Vicuña Mackenna-, el único grand cru entre los sauternes ${ }^{117}$.

Además de los chateaux, los menús y los anuncios también se refieren a vinos con denominaciones de las comarcas o pueblos. De estos, aparecen con alguna frecuencia Saint Julien, Saint Estéphe, Corton, Saint Emilion y Margaux ${ }^{118}$. Estos últimos tres nombres, junto con Pontet-Canet, quedaron posteriormente incorporados a la nomenclatura vinícola chilena.

\section{LAS ADULTERACIONES Y FALSIFICACIONES}

La adulteración del vino era tan antigua como su fabricación misma. Para limitarnos al Chile del siglo XIX, basta con recoger el comentario de Claudio Gay, quien, al referirse a la adición de cocido a los vinos, señala en una nota:

117 Benjamín Vicuña Mackenna, "La parra y el vino de California i el de Chile. Viaje del país de las crisis al mundo de las maravillas", BSNA Vol, X, $\mathrm{N}^{\circ} 14$, mayo 1878, 287-288. 
Los bodegoneros de Valparaíso piden siempre los vinos muy cargados de cocido, probablemente para disfrazar el agua que se les pone al detallarlo; en tal caso tienen que pagar algo más el precio del vino, porque el cocido por tener una cantidad mucho mayor de mosto, tiene siempre un valor doble, poco más o $\operatorname{menos}^{119}$.

El problema de la adulteración se mantuvo en el tiempo. Un manual de economía doméstica de 1876 advertía sobre las modalidades que revestía:

El vino puede contener agua o azúcar, que es la mezcla nociva, pero puede también estar adulterado con aguardiente, maqui, palo de brasil, greda o carbonato de cal, alumbre, plomo y otras sustancias metálicas que constituyen un veneno de acción lenta ${ }^{120}$.

No sorprende, pues, que los anuncios de venta de vinos destaquen su pureza. Así lo hacía Adolfo Izquierdo al declarar que los vinos de la chacra San Martín de San Bernardo son "únicamente cosechados en la chacra nombrada bajo la atención inmediata de su dueño se recomiendan por su pureza", mientras que la casa Bórquez y Ca. de Valparaíso, vendedores de vino en damajuanas, pipas y barriles al por mayor y menor, aseguraba a sus clientes potenciales que "tenemos en venta nuestros vinos siempre iguales que garantizamos puros y sin mezcla de ninguna clase" 121 .

Por otra parte también hay quejas de la falsificación o adulteración de vinos chilenos exportados. Escribiendo en el Boletín de la Sociedad Nacional de Agricultura, Nathan M. Cox se lamenta que luego de los buenos premios obtenidos por los vinos chilenos en Montevideo y Buenos Aires algunos inescrupulosos mataron "la gansa que ponía huevos de oro"

Tiente alguien de mandar allí vinos chilenos. Necesitarán tener agentes especiales que aseguren, por propia experiencia, que no venden los vinagres y venenosas mezcolanzas líquidas que sucedieron a las primeras remesas de vinos chilenos, y en las que algunos, no muchos de aquí, en reconocimiento de primeras pingües ganancias, acometieron contra la salud de aquellos pueblos. Ahí, es cierto, venden vinos espurios, bajo carátulas chilenas de fama, pero vino chileno en barril es anatema... ${ }^{122}$.

118 Guía-Almanaque de Valparaíso, [88] 16; Itinerario [105], 20-21.

119 Haigh, Caldcleugh y Radiguet [7], 247; J Miers [9], II, 300; Gay [1], II, 192n.

120 Eduvigis Casanova de Polanco, Elementos de Economía Doméstica e Higiene Casera, Santiago, Imprenta y Librería del Mercurio, 1876, 38.

121 El Ferrocarril (Santiago), 1-4-1882, 3; Almanaque comercial para el año bisiesto de 1892, Valparaíso, s.p.d.i. [Imprenta la Patria?], 1891, 108.

122 Nathan Miers Cox, "Hace más cuenta ser honrado que pícaro", BSNA Vol. XV, N 21, 20-81884, 463-465. 
Tampoco los vinos que se vendían en Chile, con etiquetas de los reputados chateaux franceses, eran lo que pretendían ser. Durante su viaje a Europa en 1870, Abdón Cifuentes visitó una fábrica de vinos en Montpellier, cuyos procedimientos describe como sigue:

Con un poco de vino carlón de Cataluña, que es vino grueso, otro tanto de agua, un poco de agua de Campeche y no sé que otro ingrediente, se fabricaba toda clase de vinos franceses: Chateau Lafite, Chateau Larose, Chateau Margot, etc. En presencia de tales falsificaciones, pregunté si se expendían estos vinos en Francia, "No" me contestaron, "Sont pour les Amériques"123.

Don Abdón agrega que cuando fue a visitar el Chateau Lafite en Burdeos, no pudo conseguir que se le vendiera botella alguna por estar toda la producción comprometida por varios años, mientras la fábrica de Montpellier le hacía pensar en la facilidad con que se conseguía Chateau Lafite en Chile, donde se encontraba hasta en los almacenes de provincia.

No era este el único que tenía tales aprensiones. Julio Menadier, escribiendo en el Boletín de la Sociedad Nacional de Agricultura, reproducía la carta de un señor Bordy sobre el arte del vino francés:

Así se explica que los vinos de Burdeos, notables por su "bouquet" especial, son producidos en sus nueve décimas partes en el sur de Francia; vinos alcohólicos pero comunes. "Vinos para rotos", como ustedes dicen aquí, porque no sirven para caballeros i gourmands; después de haber pasado a manos de los señores Bordaleses son tratados de una manera particular i mezclados convenientemente para convertirles en excelente Chateau Lafite, Chateau Margaux, Saint Julián, Medoc, Haut Sauterne, etc. etc., que solo son consumidos por las testas coronadas i la alta aristocracia del mundo entero ${ }^{124}$.

En otro artículo del citado Boletín, Benjamín Vicuña Mackenna advierte a los lectores chilenos que el Lafite "cuya marca encontrareis hoy con toda desvergüenza en las fondas de la Ligua como en los bodegones del Resbalones y el Perejil" proviene de un viñedo de unas 30 cuadras de superficie, y una producción promedio de 120 mil botellas anuales. Y termina: “¿Creeis ahora que haya llegado jamás a Chile i corrido por el paladar chileno una sola gota de Lafite, a no ser traído de regalo?"125.

De ahí que los avisos de E. Momus en los que anunciaba vinos embotellados franceses, insistía que "todos [eran] legítimos y sus marcas auténticas"126, y que la Droguería Francesa de D. Mourges y Ca. ofreciera "vinos de burdeos legítimos"127.

123 Abdón Cifuentes, Memorias, Santiago, Nascimento, 1936, I, 303.

124 Julio Menadier, "Porvenir" [83], 161.

125 Vicuña Mackenna [111] loc. cit.

126 El Mercurio, Valparaíso, 4-5-1876, 1.

127 El Ferrocarril, (Santiago), 7-11-1881, 3. 
No obstante estas declaraciones, la abundancia de testimonios en contrario y la lógica de los argumentos sobre la dudosa legitimidad de los vinos de marca que llegaban a estas costas, hacen pensar que la mayor parte de los vinos de "chateaux" que se bebían en Chile no eran tales.

\section{CONCLUSIONES}

Como es sabido, desde mediados del siglo XIX tuvo lugar una renovación en la vitivinicultura chilena tanto por efecto de la introducción de nuevas cepas como por una verdadera revolución en las técnicas de vinificación y guarda. Este proceso, que tuvo una marcada impronta francesa, no fue total; se concentró de preferencia en las provincias de Aconcagua y Talca, que, de paso, adquirieron una creciente importancia como regiones productoras. Con todo, para mediados de los años 1870 la producción anual de "burdeos" o vinos a la francesa superaba los dos millones y medio de litros contra un máximo de poco más de un millón y medio de litros de vinos tintos importados en sus distintos tipos y envases. El reconocimiento a la consiguiente mejora en la calidad del vino chileno no se limitó a las medallas obtenidas en diversas exposiciones internacionales. La prueba más efectiva del nivel de calidad alcanzado por los buenos vinos, particularmente en el caso de los tintos, fue la fuerte caída en las importaciones de aquellos tipos que se producían en el país, a partir de los años 1880. Se hace esta salvedad porque otros vinos que no tenían un equivalente local, como es el caso del champaña, el jerez y el oporto, eran importados y consumidos en grandes cantidades. Así se desprende tanto de la distribución entre los países proveedores como de las cifras desglosadas que existen para los años entre 1905 y 1913, cuando las importaciones aumentan con fuerza.

Lo anterior también confirma que la sustitución de vinos importados por nacionales no se debió a un menor poder adquisitivo de los consumidores de bolsillos profundos y paladares sensibles. El advenimiento de la prosperidad salitrera no detuvo esta tendencia, sin perjuicio de que el ritmo de las importaciones haya sido sensible a los efectos de las crisis y los aumentos de impuesto. Es cierto que, más allá de la efectiva ventaja de los vinos nacionales sobre los europeos en su relación calidad/precio, hay un innegable factor de prestigio social o un sello de distinción vinculado al producto importado, y particularmente al de origen francés. De ahí la desproporcionada presencia de vinos franceses o, al menos, con nombres franceses en los banquetes de la época. Con todo, la tendencia a favor de los vinos chilenos terminó por imponerse en el tiempo, ayudada por las restricciones al comercio exterior en los decenios posteriores al período estudiado. 